\title{
Mechanistic Considerations on Homogeneously Catalyzed Formic Acid Dehydrogenation
}

\author{
Manuel Iglesias, ${ }^{*[a]}$ Luis A. Oro* ${ }^{* a, b]}$ \\ [a] M. Iglesias, L. A. Oro. Departamento Química Inorgánica - ISQCH. Universidad de Zaragoza - CSIC. Pedro Cerbuna 12, 50009 \\ Zaragoza, Spain. E-mail: miglesia@unizar.es; oro@unizar.es.
}

[b] L. A. Oro. Centre of Research Excellence in Petroleum Refining and Petrochemicals, King Fahd University of Petroleum \& Minerals (KFUPM), Dhahran 31261, Saudi Arabia.

\begin{abstract}
The dehydrogenation of formic acid permits the production of hydrogen virtually free of carbon monoxide, which is a key requisite for its use in fuel cells. Moreover, $\mathrm{HCOOH}$ is a suitable hydrogen carrier, better in several crucial characteristics than other liquid organic hydrogen carriers, namely, low toxicity, high hydrogen content and recyclability (via $\mathrm{CO}_{2}$ hydrogenation). The most successfully employed catalysts are those based on $\mathrm{Ir}, \mathrm{Ru}, \mathrm{Rh}$ and $\mathrm{Fe}$ metal centers. The catalytic cycles through which homogeneous metal complexes operate show a wide mechanistic diversity. The nature of catalytic cycle depends mainly on the nuclearity of the active species, the type of $\mathrm{CO}_{2}$ formation step ( $\beta$-hydride elimination, hydride abstraction or outer-sphere mechanism), and whether the rate limiting step relates to $\mathrm{CO}_{2}$ or $\mathrm{H}_{2}$ formation. Different outer-sphere interactions have been proposed in the literature in order to explain the success of homogeneous catalyst, which seems to be common ground for most of the catalysts so far reported.
\end{abstract}

\section{Introduction}

The continuous rise in energy consumption worldwide, together with the negative impact of power generation from fossil fuels on global climate, has led to intensive research on alternative sustainable technologies. ${ }^{[1]}$ In this regard, hydrogen has been proposed as an alternative energy carrier/fuel, which may be produced from natural gas, biomass or water. ${ }^{[2]}$ The use of biomass or water as energy vectors would have significant implications in the sustainability and the carbon footprint of these technologies. In particular, water splitting to give $\mathrm{H}_{2}$ and $\mathrm{O}_{2}$ using sunlight (artificial photosynthesis) would provide a clean, renewable and carbon neutral source for hydrogen production. ${ }^{[3]}$ In addition, the peaks of production inherent to the intermittent nature of renewable energy sources could be exploited more efficiently if the excess energy thus produced was stored as hydrogen via water electrolysis. Nevertheless, the use of hydrogen as an energy source raises several concerns, mainly related to safety and transportation issues.

The use of fuel cells is a promising manner to generate electricity from hydrogen in stationary power units or to substitute combustion engines in vehicles. ${ }^{[4]}$ However, for fuel cell purposes, hydrogen virtually free of carbon monoxide needs to be employed (less than $10 \mathrm{ppm}$ in the mixture of gases ${ }^{[5]}$ ), which is relatively complicated to obtain from methanol reforming and the water gas shift reaction, currently the main sources of hydrogen. ${ }^{[6]}$
Homogeneously catalyzed formic acid (FA) dehydrogenation has been proposed as a means to obtain a $\mathrm{H}_{2} / \mathrm{CO}_{2} 1: 1$ mixture that can be used directly in fuel cells. ${ }^{[7]}$ These studies have sparked the interest of the scientific community in the use FA as liquid organic hydrogen carrier (LOHC). FA presents several advantages compared to the use of compressed hydrogen as an energy carrier, mainly regarding security issues and energy density (lower gravimetric/volumetric densities than FA). Certain characteristics of FA, such as the low toxicity, high hydrogen content, straightforward transportation and a feasible hydrogenation/dehydrogenation cycle makes it a more suitable $\mathrm{H}_{2}$-carrier than other $\mathrm{LOHC}$. ${ }^{[6,8]}$

The hydrogenation of $\mathrm{CO}_{2}$ to $\mathrm{HCOOH}(\mathrm{FA})$ opens the door to use this system as a zero $\mathrm{CO}_{2}$ emission cycle for hydrogen storage. The hydrogenation of $\mathrm{CO}_{2}$ has been widely explored, resulting in remarkable advances in this reaction over the last two decades. ${ }^{[9]}$ Moreover, FA is readily available from other sources such as biomass oxidation or from the hydrolysis of methyl formate, which is an abundant by-product of methanol carbonylation. ${ }^{[10]}$ Several review articles that deal with the dehydrogenation of FA have been published; $\left[{ }^{11,9 f]}\right.$ however, we believe that a comprehensive overview of the mechanistic pathways hitherto reported would offer new insights into this process. In this article we aim to review the most relevant studies on the reaction mechanisms of homogeneously catalyzed dehydrogenation of FA. In parallel to the description of the catalysts, the evaluation of their performances and the reaction conditions required for each reaction to take place, we aim to provide a mechanistic analysis that will try to connect the characteristics of the catalytic systems with their reaction pathways.

\section{Early catalytic systems}

The use of FA as a LOHC was not proposed until 2008 by Beller's and Laurenczy's groups independently. ${ }^{[7]}$ However, the dehydrogenation of FA by means of homogeneous catalysts had been described previously. Coffey reported on the selective dehydrogenation of $\mathrm{HCOOH}$ to give $\mathrm{H}_{2}$ and $\mathrm{CO}_{2}$ using several transition metal complexes as catalysts in acetic acid under reflux. ${ }^{[12]}$ Among the catalysts studied in this work, the best results were obtained with $\left[\mathrm{PtCl}_{2}\left(\mathrm{PBu}_{3}\right)_{2}\right]$, $\left[\mathrm{RuHBrCO}\left(\mathrm{PEt}_{2} \mathrm{Ph}\right)_{3}\right]$, $\left[\mathrm{RuHCl}\left(\mathrm{Et}_{2} \mathrm{PCH}_{2} \mathrm{CH}_{2} \mathrm{PEt}_{2}\right)_{2}\right], \quad\left[\mathrm{IrCl}_{3}\left(\mathrm{PEt}_{2} \mathrm{Ph}\right)_{3}\right], \quad\left[\mathrm{IrCl}_{3}\left(\mathrm{PBu}_{3}\right)_{3}\right]$, $\left[\operatorname{IrCl}(\mathrm{H})_{2}\left(\mathrm{PPh}_{3}\right)_{3}\right.$ and $\left[\operatorname{Ir}(\mathrm{H})_{3}\left(\mathrm{PPh}_{3}\right)_{3}\right]$, the latter being the most active. The use of $\left[\mathrm{IrCl}(\mathrm{CO})\left(\mathrm{PPh}_{3}\right)_{2}\right]$ under catalysis conditions led 
to the isolation of a plausible reaction intermediate, namely $\left[\operatorname{lrCl}(\mathrm{CO})(\mathrm{H})_{2}\left(\mathrm{PPh}_{3}\right)_{2}\right]$.

In 1982, Trogler and co-workers reported on the dehydrogenation of FA with catalysts $\left[\mathrm{Pt}_{2}(\mathrm{H})_{3}\left(\mathrm{PEt}_{3}\right)_{4}\right] \mathrm{BPh}_{4}$ or $[$ trans$\left.\mathrm{PtH}(\mathrm{S})\left(\mathrm{PEt}_{3}\right)_{2}\right] \mathrm{BPh}_{4}(\mathrm{~S}=\mathrm{FA}$, acetone or ethanol) in the presence of excess sodium formate. ${ }^{[13]}$ Based on experimental evidences, the authors proposed a mechanism that entails the formation in small quantities of a formate and a dihydride complexes in equilibrium with the starting materials as first step of the catalytic cycle. The dihydride complex reacts with $\mathrm{HCOOH}$ to afford the formate complex, and the decarboxylation of the latter regenerates the dihydride complex (Scheme 1).

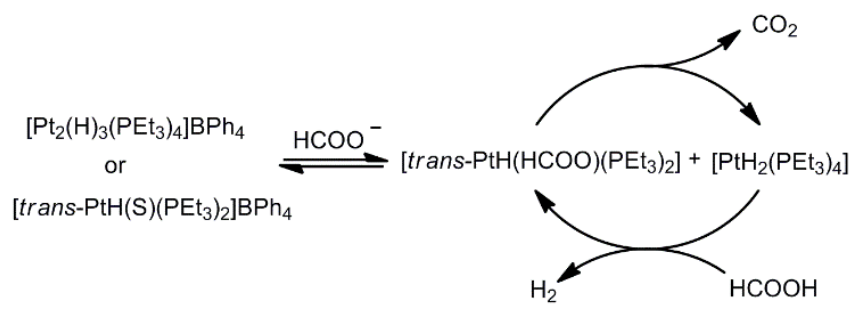

Scheme 1. FA dehydrogenation mechanism proposed by Trogler et al.. ${ }^{[13]}$

In 1998 Puddephatt et al. described a bimetallic Ru complex able to dehydrogenate FA in the presence of a base at room temperature in acetone. ${ }^{[14]}$ The active species is an unsaturated dihydride where the two $\mathrm{Ru}$ centers are linked by two bis(diphenylphosphino)methane ligands, one bridging hydride and one bridging carbonyl. Each ruthenium atom presents a terminal carbonyl ligand, one of them cis to a vacant position and the other cis to a terminal hydride. The reaction of this complex with FA yields a hydrogen molecule and a formato complex that undergoes $\mathrm{CO}_{2}$ elimination. The pathway through which the decarboxylation reaction takes place is unclear, since this $R u$ center is coordinatively saturated. Two possible intermediates were proposed by the authors (Scheme 2), ${ }^{[14 b]}$ the most likely being the $\mathrm{CO}_{2}$ bridging species, because, first, similar complexes have been isolated and, second, the unsupported terminal coordination mode for $\mathrm{CO}_{2}$ seems less likely. ${ }^{[15]}$ For the formation of this intermediate, the authors postulated a transient dissociation of the formate ligand followed by hydride abstraction-due to the lack of the vacant coordination site necessary for the $\beta$-hydride elimination reaction to occur. However, it should not be discarded that the migration of the bridging hydride ligand to a terminal position would generate a vacant site cis to the formate ligand. This type of reactivity is common in dinuclear complexes due to the lability of the hydrido ligands in these systems. ${ }^{[16]}$ Moreover, higher reaction rates of $\beta$ hydride elimination have been reported for binuclear complexes when compared to their mononuclear analogues. ${ }^{[17]}$
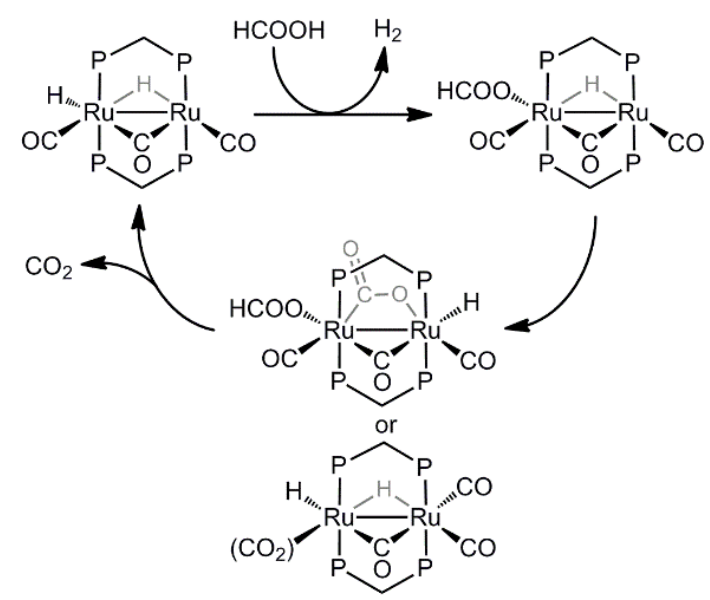

Scheme 2. FA dehydrogenation mechanism proposed by Puddephatt et al.. ${ }^{[14 b]}$

More recently, a study by Lao et al. in 2003 describes the catalytic activity in $\mathrm{CO}_{2}$ hydrogenation and $\mathrm{FA}$ dehydrogenation using heterodinuclear complexes featuring a Ru-Mo or a Ru-W core sustained by a bridging bis(diphenylphosphino)methane ligand. ${ }^{[18]}$ These complexes show catalytic activity in the hydrogenation of carbon dioxide to FA and the reverse reaction, presenting significantly higher reaction rates for the latter. The authors proposed a catalytic cycle (Scheme 3 ) that entails, as first step, the abstraction of the proton from a molecule of FA by the dinuclear core. This results in the formation of a bridging hydride ligand, the loss of the intermetallic $\mathrm{Ru}-\mathrm{M}$ bond and the generation of a formate counterion. Subsequently, the formate ion breaks the $\mathrm{Ru}-\mathrm{H}$ bond to give an intermediate where one of the oxygen atoms of the formate interacts with the Ru center and the other with the hydride ligand at $\mathrm{M}$. At this stage, reductive elimination of $\mathrm{CO}_{2}$ takes place, which results in the formation of two hydrides, a $\mathrm{Ru}-\mathrm{H}$ and an $\mathrm{M}-\mathrm{H}$ (although the mechanism, whether it is $\beta$ hydrogen elimination or hydride abstraction, is not yet clear). The acidic character of the M-hydride and the more hydridic nature of the $\mathrm{Ru}-\mathrm{H}$ bond results in a certain degree of interaction between them, somewhat reminiscent of a dihydrogen bridging ligand. Finally, the reductive elimination of $\mathrm{H}_{2}$ regenerates the active species, thus restarting the catalytic cycle.

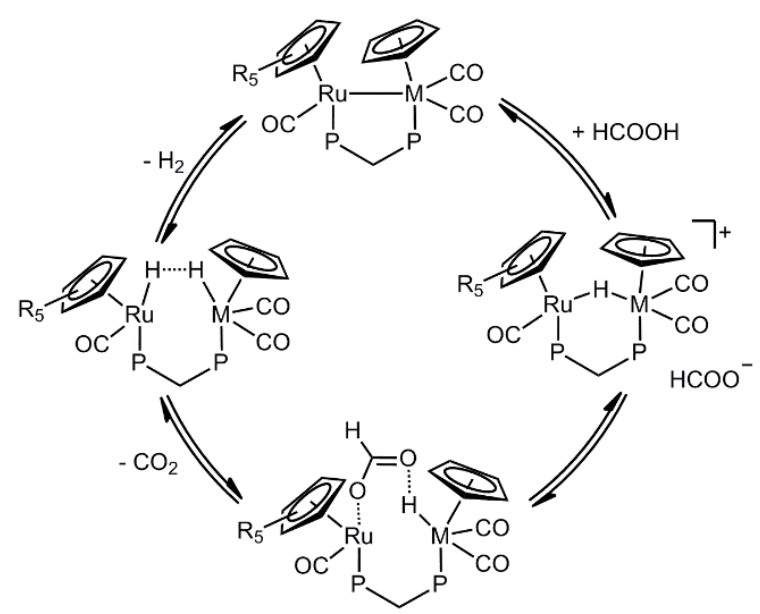

Scheme 3. Interconversion between $\mathrm{H}_{2} / \mathrm{CO}_{2}$ and $\mathrm{HCOOH}$. ${ }^{[18]}$ 


\section{Iridium catalysts}

Iridium complexes have been so far the most widely studied FA dehydrogenation catalysts from a mechanistic viewpoint. They present a broad diversity of reactions pathways depending on the nature of the ligand system and the reaction media. Outer-sphere interactions have been proved crucial to explain the high activity of many of these catalysts. A significant example is the IrbisMETAMORPhos catalyst reported by Reek and co-workers. ${ }^{[19]}$ This catalyst has shown excellent activities in $\mathrm{HCOOH} / \mathrm{Et}_{3} \mathrm{~N}$ 5:2 mixtures, and also in solution with and without the use of an external base. In the case of the latter, when polar solvents where employed, lower activities were reported, probably because the formate anion $\left(\mathrm{HCOO}^{-}\right)$coordinates better to the vacant coordination site trans to the hydride. In the absence of a base, $\mathrm{HCOOH}$ needs to compete with the solvent for the vacant site. The catalyst performs well even in neat FA, although notably lower rates were reported. The proposed mechanism (Scheme 4), based on theoretical calculations and experimental evidences, entails initially the coordination of $\mathrm{HCOOH}$ at the vacant axial site by the oxygen atom of the carbonyl group-supported by a hydrogen bond interaction between the $\mathrm{OH}$ 's proton and the oxygen at the sulfonamide. The rearrangement of the intermediate thus obtained renders a new species that features the $\mathrm{CH}$ and $\mathrm{OH}$ protons interacting, respectively, with the Ir center and the $\mathrm{N}$ atom of the bisMETAMORPhos ligand. In the next step, a $\mathrm{CO}_{2}$ molecule is formed by concomitant hydride transfer and $\mathrm{N}$ protonation of the ligand. The resulting dihydride complex releases $\mathrm{H}_{2}$ assisted by a new molecule of $\mathrm{FA}$, which protonates one of the hydride ligands while it deprotonates the bisMETAMORPhos NH moiety (Figure 1), thus regenerating the active species and the $\mathrm{HCOOH}$ molecule.

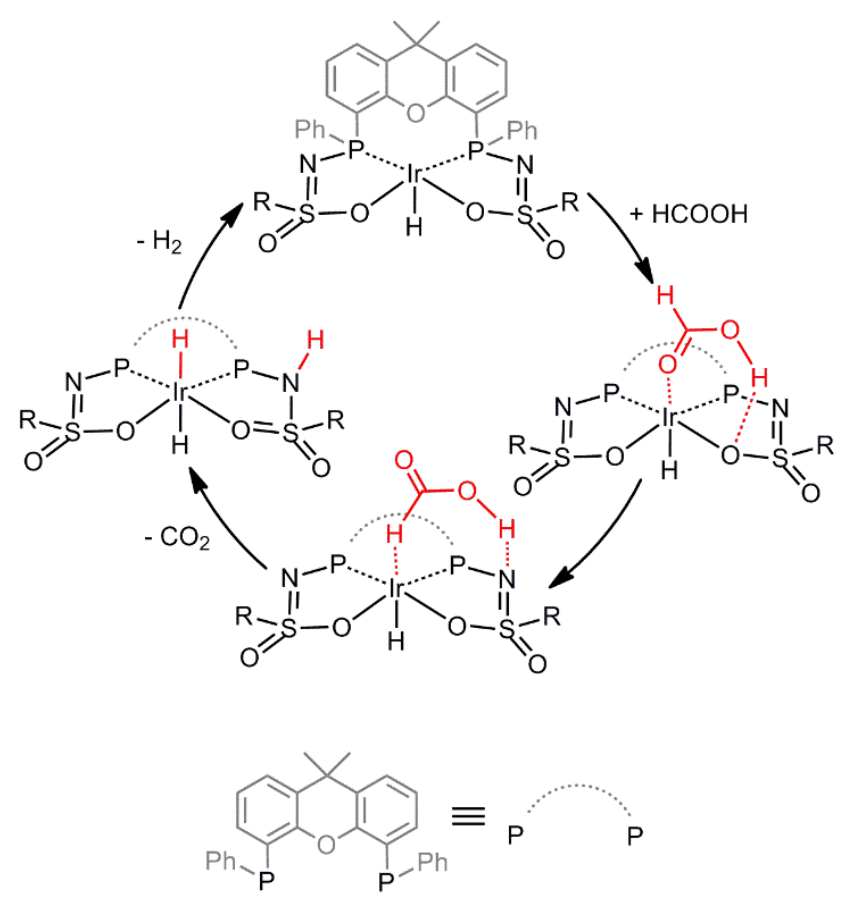

Scheme 4. Catalytic cycle proposed for Ir-bisMETAMORPhos. ${ }^{[19]}$

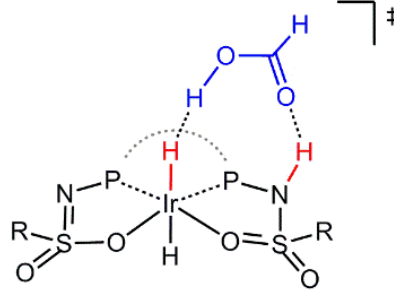

Figure 1. Transition state proposed for the FA assisted release of $\mathrm{H}_{2}{ }^{\left[{ }^{[19]}\right.}$

This mechanism, therefore, is triggered by a bifunctional catalyst that facilitates an outer-sphere pathway. Remarkably, a hydride transfer is proposed instead of the more common $\beta$-hydride elimination, which turns out to be the rate determining step of the reaction according to the kinetic isotope effect (KIE) values calculated for the reaction (performed with HCOOD and DCOOH). Other Ir systems with the capacity to undergo outer sphere interactions also present the elimination of $\mathrm{CO}_{2}$ (via $\beta$-hydride elimination or hydride transfer) as rate limiting step. For example, $\mathrm{KIE}$ studies revealed that for complexes 1-3 (Figure 2) the rate limiting step is the elimination of $\mathrm{CO}_{2}$, while for complexes 4-5 (Figure 2), $\mathrm{H}_{2}$ elimination would be the most energetically demanding step. ${ }^{[20]}$

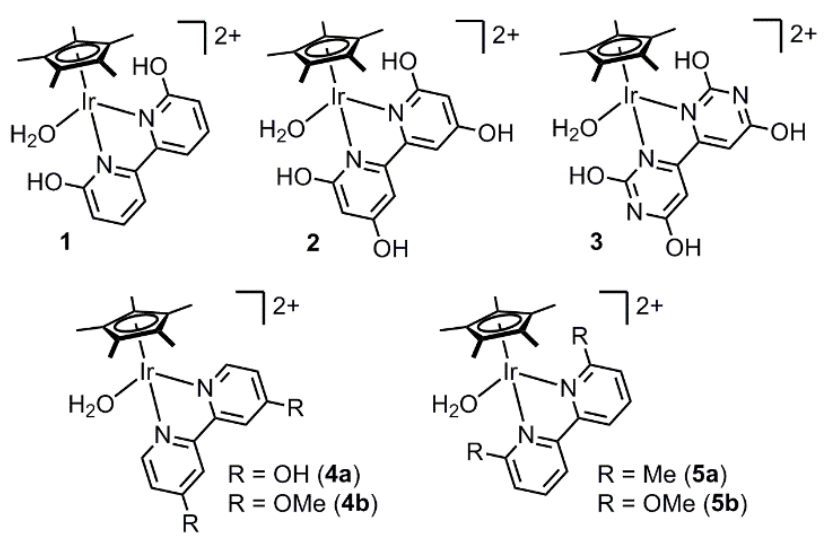

Figure 2. Depiction of complexes 1-5

This observation was explained in terms of the ability of complexes 1-3 to assist the elimination of $\mathrm{H}_{2}$ by means of outer sphere interactions. On the other hand, the incapability of complexes 4-5 to aid $\mathrm{H}_{2}$ elimination, attributable to the fact that they do not present ortho-OH groups, increases the energy barrier of this step. Complexes 1-3 present ortho-OH groups that are able to lock a hydronium ion in the proximity of the hydride ligand, thus favoring $\mathrm{H}_{2}$ formation via hydride protonation under acidic conditions (Figure 3 ).

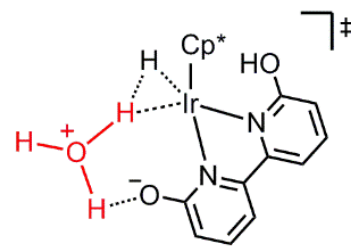


Figure 3. Transition state proposed for the $\mathrm{H}_{3} \mathrm{O}^{+}$-assisted elimination of $\mathrm{H}_{2}$ using 1 as catalyst. ${ }^{[20]}$

The term proton-responsive was employed to describe complexes 1-3, since they improve their activity with increasing $\mathrm{pH}$ values, reaching a maximum at $\mathrm{pH} 4.0$ (approximately the $\mathrm{pK}_{\mathrm{a}}$ of complex 1). However, under more acidic conditions the hydroxyl groups stay neutral, which results in similar catalytic activity for proton-responsive and non-proton-responsive complexes. ${ }^{[21]}$

The generic catalytic cycle that complexes 1-5 follow for the dehydrogenation of FA is depicted in Scheme 5 (using 1 as catalyst), and it involves: (i) formation of the formate complex; (ii) $\mathrm{CO}_{2}$ elimination; (iii) $\mathrm{H}_{2}$ elimination and regeneration of the aquo complex. ${ }^{[22]}$

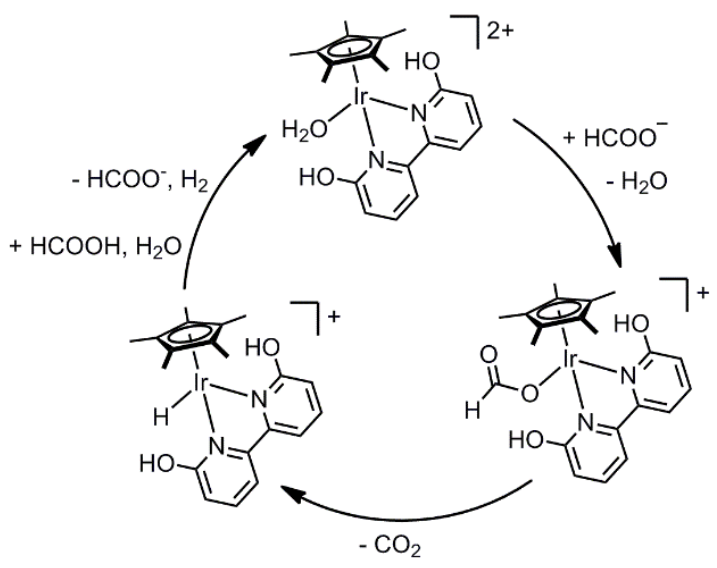

Scheme 5. Catalytic cycle proposed for complex $1 .^{22}$

The related proton-switchable complex 6 (Scheme 6 ) is one of the few catalyst able to promote the hydrogenation of $\mathrm{CO}_{2}$ and the dehydrogenation of $F A$, thus allowing for reversible $\mathrm{H}_{2}$ storage in $\mathrm{CO}_{2 .}{ }^{[23]}$ The activity of the catalyst (i.e. hydrogenation vs dehydrogenation) can be switched by $\mathrm{pH}$-tuning. The protonated catalyst (6) triggers the dehydrogenation reaction, while the deprotonated adduct (6') catalyzes the hydrogenation of $\mathrm{CO}_{2}$. Remarkably, in the case of the dehydrogenation reaction, the presence of the hydroxyl groups seems to have no significant effect on the activity of the catalyst since similar rates were obtained for the unsubstituted 2,3'-bipyridine ligand. Conversely, the presence of the hydroxyl groups in the ligand scaffold has been proposed to be crucial to catalyst activation, which has been attributed to the electronic donating effect of the $\mathrm{OH}$ moieties. ${ }^{[24]}$

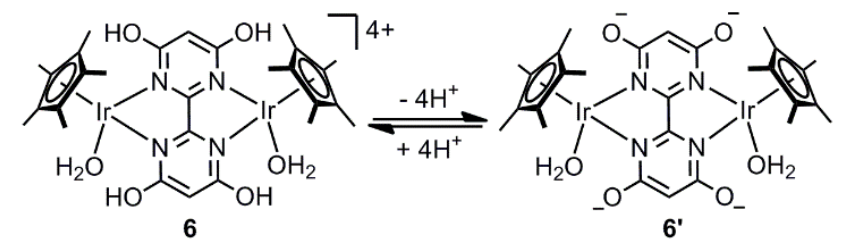

Scheme 6. Depiction of complexes 6 and $\mathbf{6}^{\text {' }}{ }^{[23]}$
Complexes derived from the $\mathrm{IrCp}^{*}$ scaffold featuring cyclometallated aryl-2-imidazoline ligands have also been described as excellent catalysts for FA dehydrogenation in neat $\mathrm{HCOOH}-\mathrm{Et}_{3} \mathrm{~N}$ 5:2 mixtures. ${ }^{[25]}$ Outer-sphere interactions were invoked in order to explain the prominent performance of this class of catalysts, based on the fact that the absence of the remote $\mathrm{NH}$ moiety thwarts the catalytic reaction. Initial studies by Xiao et al. on the mechanism of the reaction suggested that the active species (7) deprotonates $\mathrm{HCOOH}$ by means of the remote $\mathrm{N}$ atom, with concomitant coordination of the formate ion to the vacant site at the $\mathrm{Ir}$ center. Subsequently, $\mathrm{CO}_{2}$ elimination would take place to give a hydride complex with a formate hydrogen bonded to the remote $\mathrm{NH}$ function. The formate would transfer the proton from the remote to the coordinated $\mathrm{N}$ atom (Figure 4). Finally, a dihydrogen complex is formed by protonation of the hydride ligand according to a Noyori-type mechanism, ${ }^{[26]}$ and the release of $\mathrm{H}_{2}$ regenerates the 16-electron active species.

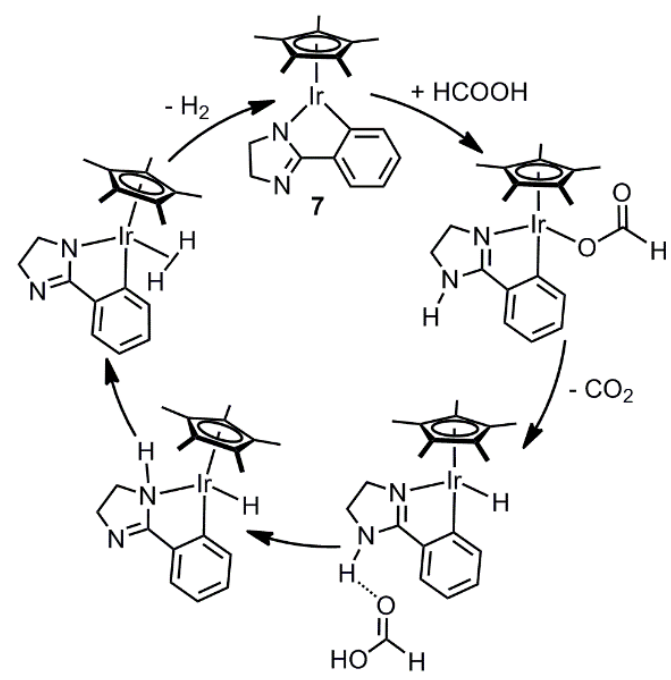

Scheme 7. Mechanism proposed by Xiao and co-workers. ${ }^{[25]}$

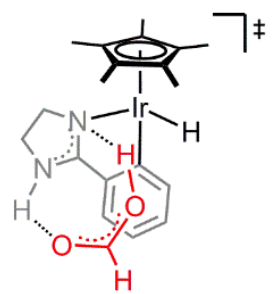

Figure 4. Transition state proposed for the proton transfer assisted by the formate anion. ${ }^{26}$

However, theoretical calculations performed by Zhang et al. discard the pathway proposed by Xiao's group, and suggest an alternative mechanism by which two molecules of FA are required-one acts as hydrogen source and the other as $\mathrm{H}$-shuttle (Figure 5). ${ }^{[27]}$ This mechanism is based on the capacity of FA molecules to form stable dimers in solution by means of hydrogen bonding interactions, since a single FA molecule is incapable of linking the two sites of the bifunctional catalysts (namely, Ir and $\mathrm{NH}) .{ }^{[28]}$ The remote metal-ligand cooperation entails the protonation of the hydride ligand in $\mathbf{8}$ via $\mathrm{H}$-transfer from the 
distant $\mathrm{N}$ atom by means of a $\mathrm{HCOOH} \cdots \mathrm{HCOOH}$ dimer to form $\mathrm{H}_{2}$, the rate-limiting step. Elimination of $\mathrm{H}_{2}$ leads to the formation of a $\mathrm{HCOOH} \cdots \mathrm{HCOOH}$ dimer bridging the remote $\mathrm{N}$ atom and the Ir center. Subsequent reorganization affords a formate ligand stabilized by a $\mathrm{HCOOH}$ molecule linked to the remote $\mathrm{NH}$ unit. Finally, $\mathrm{CO}_{2}$ is liberated via $\beta$-hydride elimination reaction (Scheme 8).

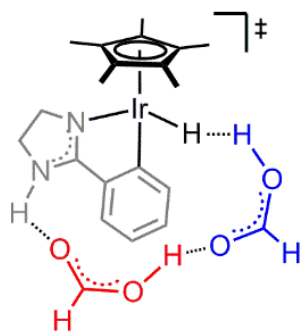

Figure 5. Transition state for the proton transfer proposed by Zhang's group. ${ }^{[27]}$

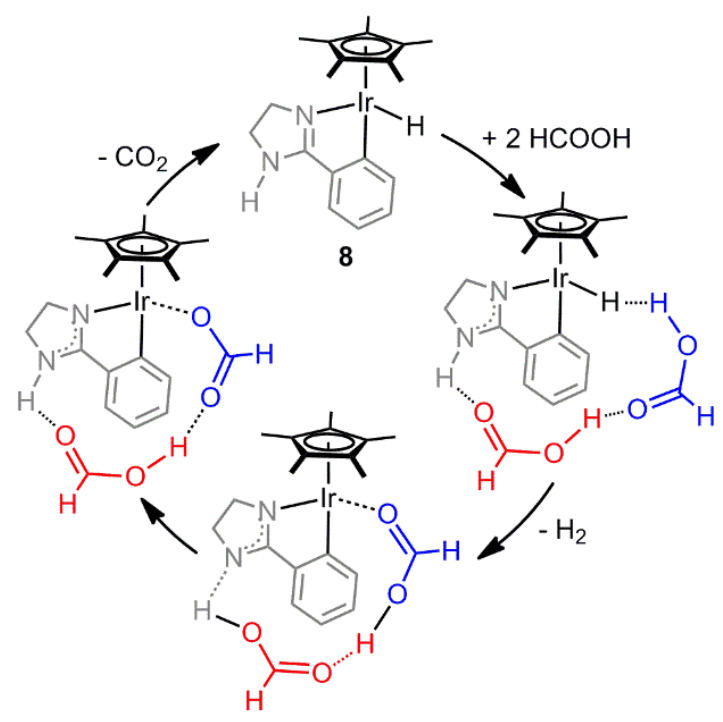

Scheme 8. Mechanism proposed by Zhang and co-workers. ${ }^{[27]}$

The beneficial role of ligands featuring $\mathrm{N}-\mathrm{H}$ bonds was further demonstrated by Ikariya and Kayaki in a study of the catalytic activity of complex 9. ${ }^{[29]}$ This catalyst is active for the dehydrogenation of $\mathrm{FA}$ in the absence of base at room temperature, even in pure water, although its low solubility leads to a decrease of activity compared to $1: 1$ mixtures 1,2dimethoxyethane (DME) / water.

Remarkably, the addition of water to DME solutions results in an enhancement of the catalytic activity, which was explained in terms of a proton-relay mechanism triggered by the $\mathrm{NH}$ moiety (Scheme 9). The proton of the $\mathrm{NH}$ group interacts with the oxygen atom of a water molecule by hydrogen bonding, placing one of the acidic hydrogen atoms of $\mathrm{H}_{2} \mathrm{O}$ in close proximity of the hydrido ligand in 10. This allows a hydrogen-hydrogen interaction that results in the protonation of the hydride and subsequent formation of a hydrogen molecule. Thus, the bifunctional nature of the catalyst permits the reduction of the activation energy of the process by lowering the energy barrier of the rate limiting step, the protonation of the hydride ligand to produce $\mathrm{H}_{2}$ according to
$\mathrm{KIE}$ studies. Further proof that supports the role of the $\mathrm{NH}$ group is that complex 11 (Figure 6), the methylated version of the reaction intermediate $\mathbf{1 0}$, shows noticeably lower activities than 10 (or 9).

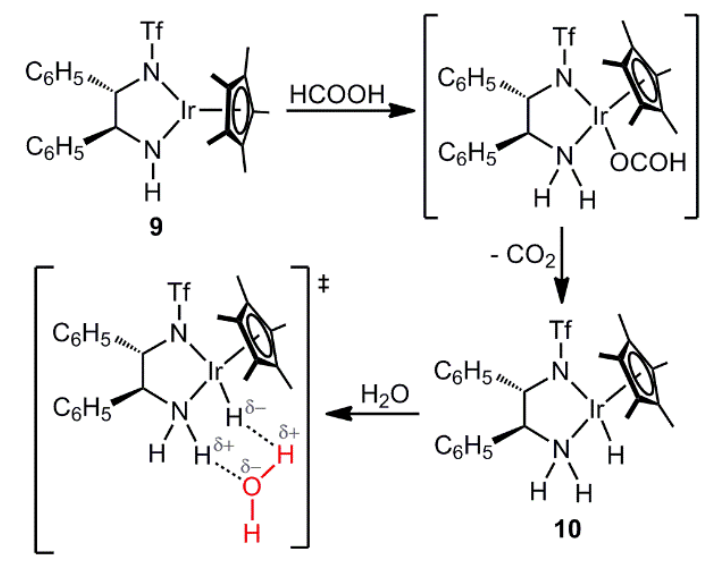

Scheme 9. Activation of complex 9 and $\mathrm{H}_{2} \mathrm{O}$ assisted $\mathrm{H}_{2}$ formation. [29]

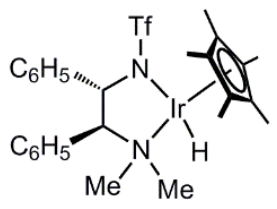

11

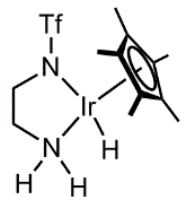

12
Figure 6. Depiction of complex 11 and 12.

Cyclometallation of the phenyl groups at the backbone of the diamine ligand leads to catalyst deactivation. The related complex 12 (Figure 6), without phenyl substituents, prevents the cyclometallation reaction and confers a higher thermic stability to the catalyst, thus improving its performance. ${ }^{[30]}$

Complex 13 is, to the best of our knowledge, the best homogeneous catalyst hitherto reported in neat FA. The use of pure FA permits the use of a reaction mixture with higher weight per cent of $\mathrm{H}_{2}$ than those that require a co-solvent. A detailed reaction mechanism based on a dinuclear Ir catalyst has been proposed. This postulation was supported on the identification of various reaction intermediates (14-16) and on kinetic studies (Schemes 10 and 11). ${ }^{[31]}$

The activation of the precatalyst, 13 , gives rise to the formation of the dinuclear complex 14 in a buffered solution FA, which further reacts to afford 15, the active species (Scheme 10). Intermediate 15 is in equilibrium with 16 in the presence of formate. The protonation of one of the terminal formate ligands of $\mathbf{1 6}$ by $\mathrm{HCOOH}$ leads to the transition state depicted in Figure 7, resulting in the generation of a $\mathrm{H}_{2}$ molecule. The authors suggest that this step is rate limiting based on the remarkably favorable entropy and the marked $\mathrm{KIE}$. The former also indicates the elimination of a molecule of gas in this step. The resulting intermediate reacts with a new molecule of FA that triggers the generation of a second $\mathrm{H}_{2}$ molecule, with concomitant formation of a dinuclear species with 4 formate ligands (2 terminal and 2 bridges). Finally, elimination of two $\mathrm{CO}_{2}$ molecules regenerates the active species 15 (Scheme 11). 


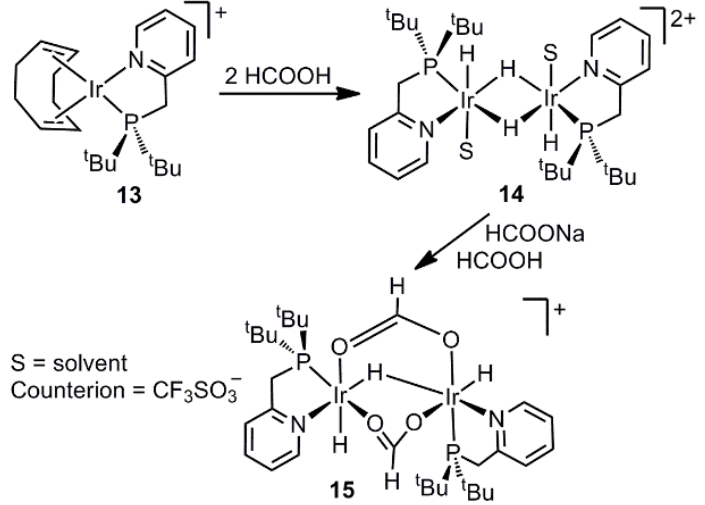

Scheme 10. Activation of complex 13 and formation of $15^{[31]}$

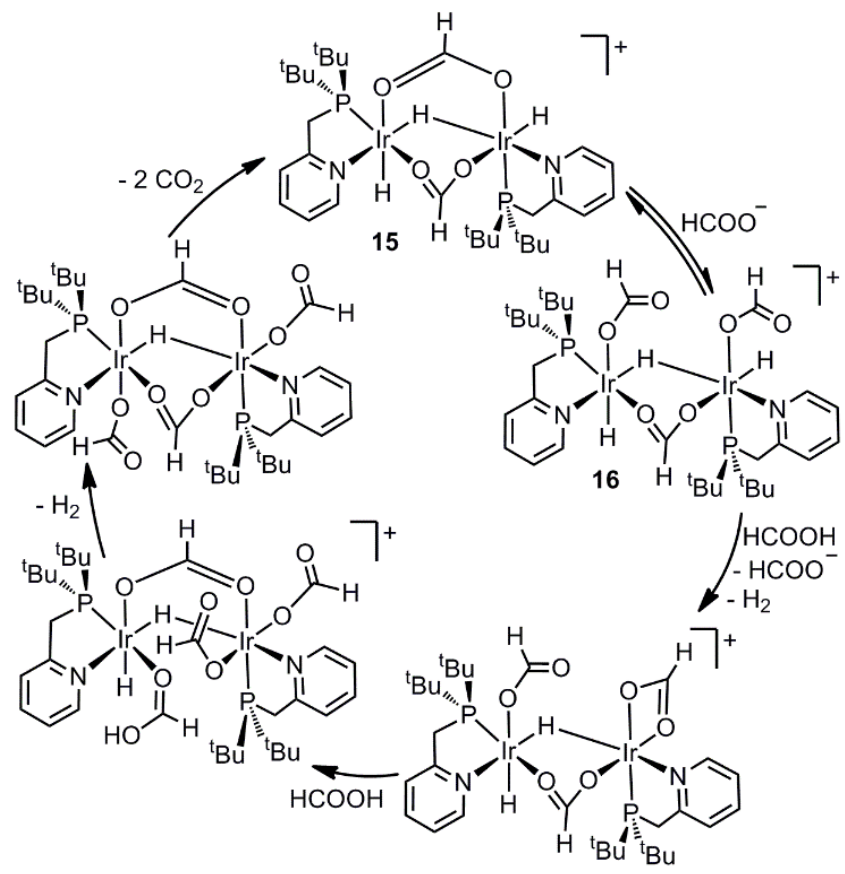

Scheme 11. Catalytic cycle proposed for the dehydrogenation of FA by complex 15 (counterion = trifluoromethanesulfonate) ${ }^{[31]}$

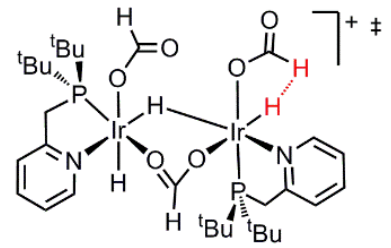

Figure 7. Proposed transition state for the $\mathrm{H}_{2}$ formation/elimination step from intermediate $16 .{ }^{31}$

Another dinuclear complex that shows good activities in FA dehydrogenation is $\mathbf{1 7}$, which features a heterodinuclear Rh-Ir framework. However, the proposed catalytic cycle suggests that only the Ir center participates in the mechanism (Scheme 12). ${ }^{\left[{ }^{[2]}\right.}$ The maximum rate for this reaction was observed at $\mathrm{pH} 3.8$ (in water at ambient temperature). The reaction mechanism entails the substitution of a coordinated water molecule by the formate ion in equilibrium with FA. Subsequently, a $\beta$-hydride elimination step was invoked by the authors to explain the generation of a $\mathrm{CO}_{2}$ molecule. Finally, the rate determining step, according to $\mathrm{KIE}$ studies, is the protonation of the hydrido ligand to produce a molecule of $\mathrm{H}_{2}$.

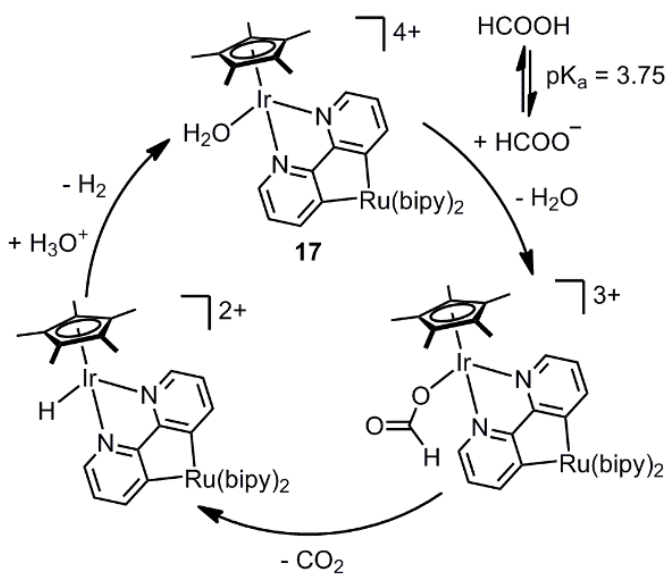

Scheme 12. Catalytic cycle proposed for complex 17. ${ }^{[32]}$

A recent contribution by Gelman and Schapiro entails the use of Ir-PCP bifunctional catalysts for the dehydrogenation of FA in DME solutions and neat. The most active of the complexes reported in this work features a PCP ligand with two dangling $\mathrm{NH}_{2}$ moieties (18), one of them being situated in the proximity of the metal center, which plays a key role in the reaction mechanism. ${ }^{[33]}$ Excellent TON and TOF values were reported even in the absence of solvent at $70^{\circ} \mathrm{C}$ ( 383000 and $11760 \mathrm{~h}^{-1}$, respectively). The proposed catalytic cycle entails, in first stage, the protonation on the $\mathrm{NH}_{2}$ moieties of 18 by FA. One of the ammonium salt thus formed, namely the one in close proximity of the metal center, protonates the hydride ligand at $\mathbf{1 8}$ ' to produce a hydrogen molecule. The vacant position generated by $\mathrm{H}_{2}$ loss is stabilized by interaction with the (now deprotonated) $\mathrm{NH}_{2}$ group in 18". Subsequently, addition of a new molecule of FA protonates again the $\mathrm{NH}_{2}$, concomitantly generating a formate (18'"'). At this point, experimental and theoretical studies suggest that the $\beta$-hydride elimination to regenerate $\mathbf{1 8}$ ' is assisted by the dangling ammonium functionality, which aids the cleavage of the $\mathrm{Ir}-\mathrm{O}$ bond via hydrogen bond interactions. Finally, this allows the $\mathrm{H}$ abstraction reaction to happen, with the ensuing elimination of a $\mathrm{CO}_{2}$ molecule and the regeneration of 3' (Scheme 13). 


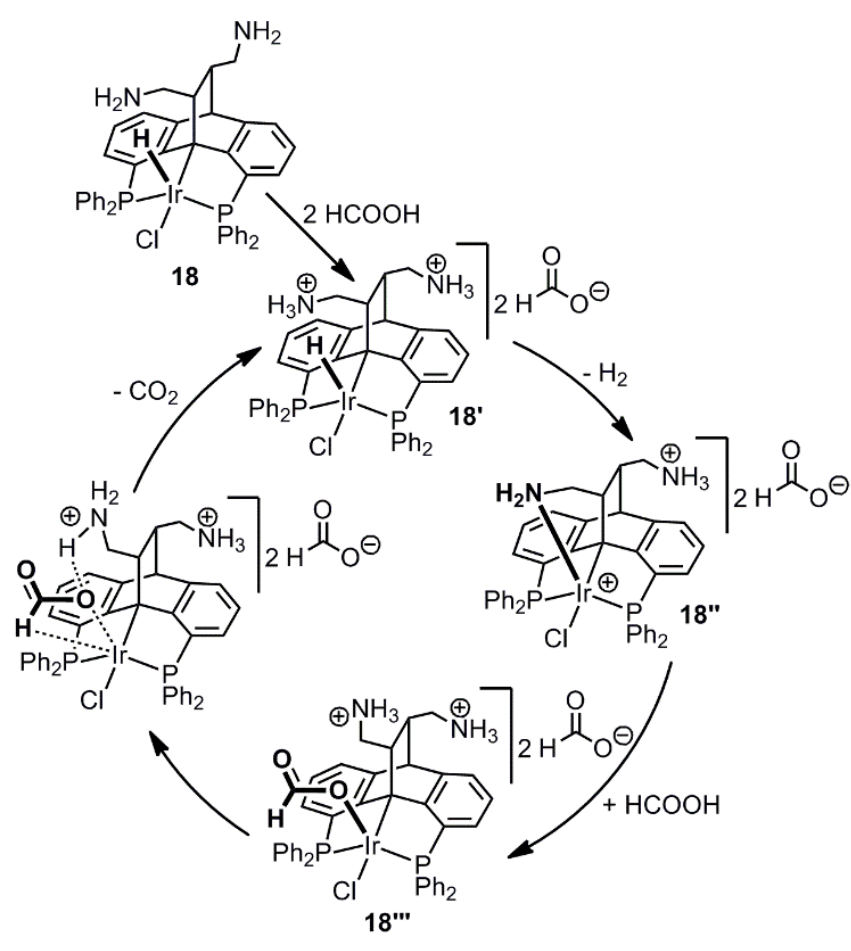

Scheme 13. Catalytic cycle proposed for complex $18 .^{[33]}$

Mechanisms for the reversible interconversion between $\mathrm{HCOOH}$ and $\mathrm{H}_{2} / \mathrm{CO}_{2}$ have also been described, but we consider that they are beyond the scope of this review. ${ }^{[34]}$

\section{Ruthenium catalysts}

Ruthenium-based organometallic complexes have shown excellent activities in FA dehydrogenation reactions;:[35][7a-b] however, the mechanistic calculation on these type of catalyst are rather scarce.

The first mechanism promoted via a Ru complex was proposed by Wills et al. in 2009; which, remarkably, seems to be a common pathway for various ruthenium catalysts for FA dehydrogenation using the azeotropic mixture 5:2 (molar) $\mathrm{HCOOH} / \mathrm{Et}_{3} \mathrm{~N}$; namely, $\left[\mathrm{RuCl}_{2}(\mathrm{DMSO})_{4}\right], \quad\left[\mathrm{Ru}\left(\mathrm{NH}_{3}\right)_{6}\right] \mathrm{Cl}_{2}, \quad \mathrm{RuCl}_{3} .{ }^{[36]}$ The dinuclear intermediates are reminiscent of those reported previously by Puddephatt et al. (see section 2). ${ }^{[14]}$

The pre-catalysts $\left[\mathrm{RuCl}_{2}(\mathrm{DMSO})_{4}\right],\left[\mathrm{Ru}\left(\mathrm{NH}_{3}\right)_{6}\right] \mathrm{Cl}_{2}$ and $\mathrm{RuCl}_{3}$ were proposed to convert into 19 under the reaction conditions based on reactivity and NMR studies. Subsequently, addition of formate to 18 brakes one of the formate bridges to give a new intermediate that features two terminal formate ligands. Reaction with thriethylammonium cation generates a molecule of hydrogen and a molecule of carbon dioxide, probably via a $\mathrm{Ru}-\mathrm{H}$ intermediate, with concomitant formation of the dibridged species 19 (Scheme 14). It is noteworthy that addition of $\mathrm{PPh}_{3}$ was described to lower the catalytic activity of the system, probably due to the obstruction of key coordination sites.

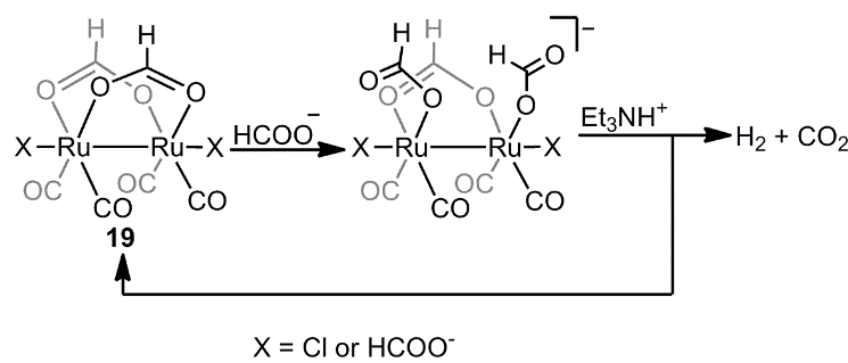

Scheme 14. FA dehydrogenation mechanism proposed by Wills et al.. ${ }^{[36]}$

In contrast with the studies by Wills et al., Laurenczy and coworkers reported a dramatically different reaction mechanism when a similar ruthenium pre-catalyst, namely trans$\left[\mathrm{Ru}\left(\mathrm{H}_{2} \mathrm{O}\right)_{4}\left(\mathrm{PMe}_{3}\right)_{2}\right]^{2+}\left(\mathbf{2 0}\right.$, Scheme 15), ${ }^{[37]}$ was used for the dehydrogenation of aqueous solutions of $\mathrm{HCOOH} / \mathrm{HCOONa}(9: 1)$. In this case, the proposed mechanism entails exclusively mononuclear species. Initially, one of the $\mathrm{H}_{2} \mathrm{O}$ ligands of $\mathbf{2 0}$ is substituted by a formate anion to give $\mathbf{2 1}$, which undergoes $\beta$ hydride elimination of the formato ligand, thus affording 22-the main species observed in solution under catalytic conditions. The dissociation of $\mathrm{CO}_{2}$ to yield $\mathbf{2 3}$ (not observed in solution under catalytic conditions) was proposed as the rate limiting step. The slower catalytic cycle (Scheme $15 \mathrm{~A}$ ) requires the reaction of $\mathbf{2 3}$ with $\mathrm{HCOOH}$, which leads to protonation of one of the hydrido ligands and the formation of a dihydrogen intermediate. The catalytic cycle is closed by ejection of a $\mathrm{H}_{2}$ molecule and coordination of $\mathrm{H}_{2} \mathrm{O}$ in the vacant site thus generated. The reaction of $\mathbf{2 3}$ with formate would initiate the fast catalytic cycle (Scheme 15 B). $\beta$-hydride elimination from this new formato complex renders the $\mathrm{CO}_{2}$ adduct, which plausibly dissociates the $\mathrm{CO}_{2}$ ligand more readily than $\mathbf{2 2}$ due to the fact that the former presents a hydride in trans position; in contrast to $\mathbf{2 2}$, which features a trans $\mathrm{H}_{2} \mathrm{O}$ ligand. Analogously to cycle $\mathbf{A}$ (Scheme 15), protonation of one of the hydrides by $\mathrm{HCOOH}$ and release of $\mathrm{H}_{2}$ closes the catalytic cycle.

It is worth mentioning that the authors supported the postulated mechanism on meticulous NMR studies, and all the numbered complexes in the cycle were identified by means of multinuclear NMR experiments. 


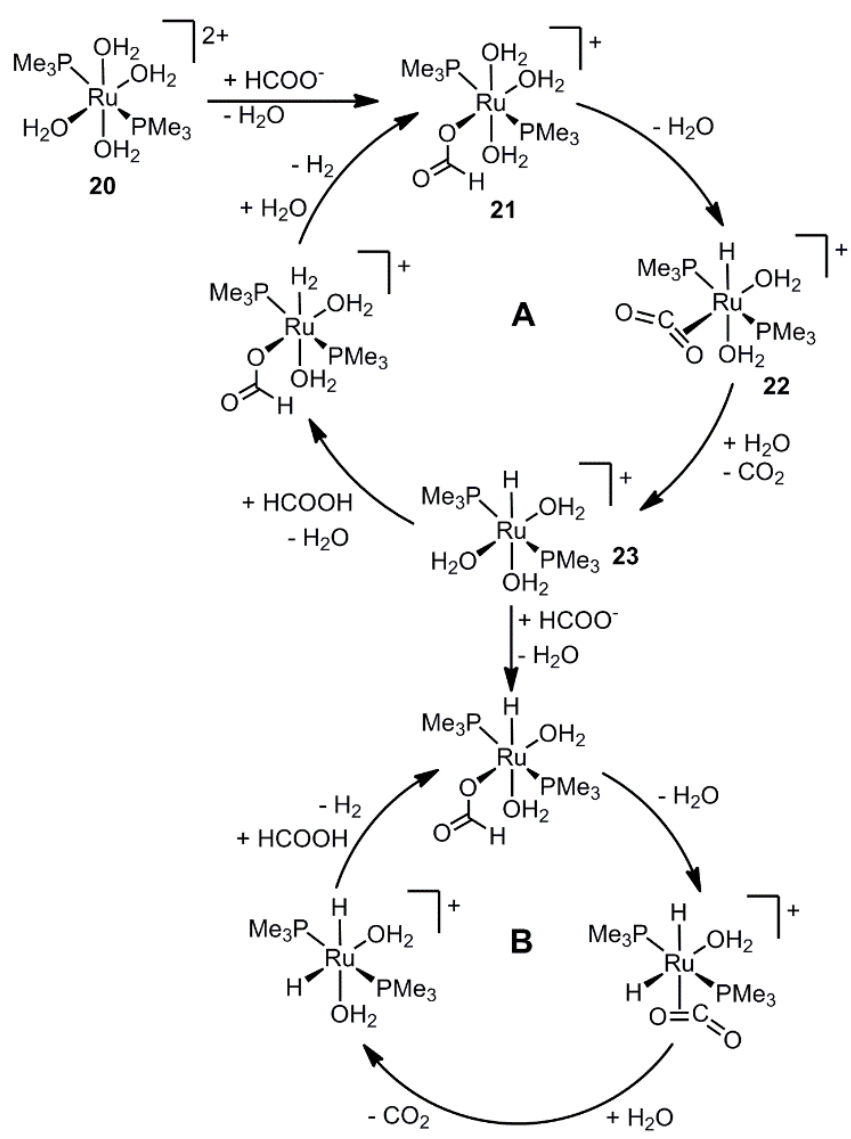

Scheme 15. Proposed catalytic cycle for the dehydrogenation of FA by complex 19 in an aqueous solution of $\mathrm{HCOOH} / \mathrm{HCOONa}{ }^{[37]}$

Peruzzini, Gonsalvi and Beller also reported catalytic cycles based on monometallic species for pre-catalysts 24 and 25 in FAamine mixtures (Figure 8). ${ }^{[38]}$ Remarkably, detailed mechanistic studies suggest that $\mathbf{2 4}$ operates by inner-sphere pathways while the use of $\mathbf{2 5}$ triggers an outer-sphere mechanism, plausibly owing to the presence of three easily accessible coordination sites in the latter.

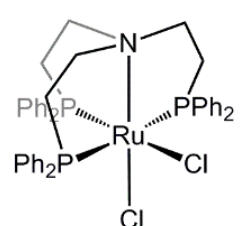

24

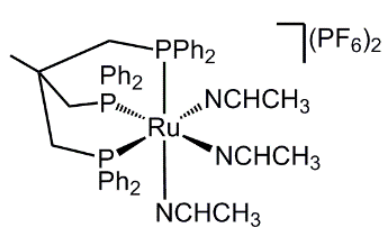

25
Figure 8. Depiction of pre-catalysts $\mathbf{2 3}$ and $\mathbf{2 4}$.

Reaction of pre-catalyst $\mathbf{2 4}$ with 1 equivalent of formate leads to the hydrochloride intermediate $\mathbf{2 6}$ via substitution of the cis chloride ligand, followed by $\mathrm{CO}_{2}$ elimination according to a dissociative mechanism. Intermediate $\mathbf{2 6}$ is the origin of the two interconnected catalytic cycles that the authors postulated for $\mathbf{2 4}$ (Scheme 16). Addition of FA to $\mathbf{2 6}$ affords the dihydrogen complex 27 via protonation of the hydrido ligand. $\mathrm{H}_{2}$ dissociation and concomitant chloride coordination affords $\mathbf{2 8}$, which subsequently undergoes chloride substitution by a formate anion to yield $\mathbf{2 7}$. $\beta$ -
Hydride elimination regenerates 26 and releases a $\mathrm{CO}_{2}$ molecule (Scheme 16 A). In the case of catalytic cycle B (Scheme 16), the first step entails the substitution of the chloride ligand in $\mathbf{2 6}$ by a formate ion to give 29. Protonation of the hydrido ligand in $\mathbf{2 9}$ yields 30 , which releases the thus formed $\mathrm{H}_{2}$ ligand. The vacant site generated by $\mathrm{H}_{2}$ dissociation permits the $\beta$-hydride elimination reaction that produces the $\mathrm{CO}_{2}$ molecule and, upon coordination of the chloride counterion, regenerates 26 . Although cycle A presents a lower activation energy, both cycles may operate under the reaction conditions.

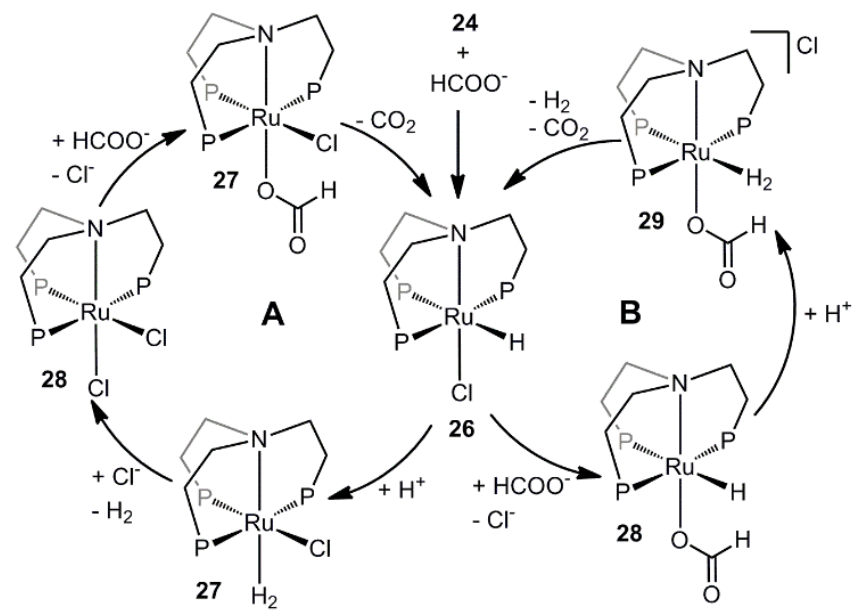

Scheme 16. Interconnected catalytic cycles proposed for pre-catalysts $24 ; \mathrm{P}=$ $\mathrm{PPh}_{2 .}{ }^{[38]}$

NMR studies of pre-catalyst 25 suggest that no hydride species are formed throughout the catalytic cycle (Scheme 17). Based on reactivity studies it was postulated that the reaction of $\mathbf{2 5}$ with formate affords 31 , the active species, which features a $\mathrm{k}-\mathrm{O}$ and a $\mathrm{K}^{2}-\mathrm{O}, \mathrm{O}^{\prime}$ ligands coordinated trans to the tridentate phosphine. Addition of FA to 31 renders an intermediate that contains two $\mathrm{K}$ $\mathrm{O}$ formate ligands and a $\mathrm{k}-\mathrm{O}$ coordinated FA molecule. Finally, the regeneration of the active species and the formation of $\mathrm{CO}_{2}$ and $\mathrm{H}_{2}$ are explained by means of a transition state that entails the cleavage of the formate's $\mathrm{C}-\mathrm{H}$ bond. This occurs via protonation of the $\mathrm{CH}$ 's hydrogen by the coordinated FA molecule (Figure 9).

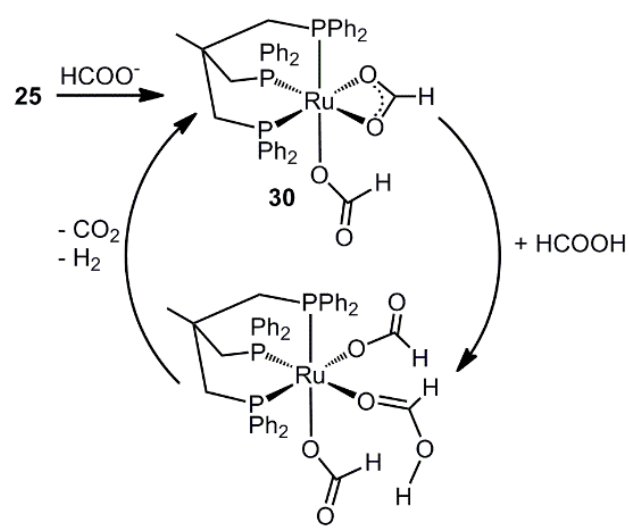

Scheme 17. Catalytic cycle proposed for the dehydrogenation of FA in a mixture $\mathrm{HCOOH} / \mathrm{Et}_{3} \mathrm{~N}(5: 2)$ using pre-catalyst $25 .^{[38]}$ 


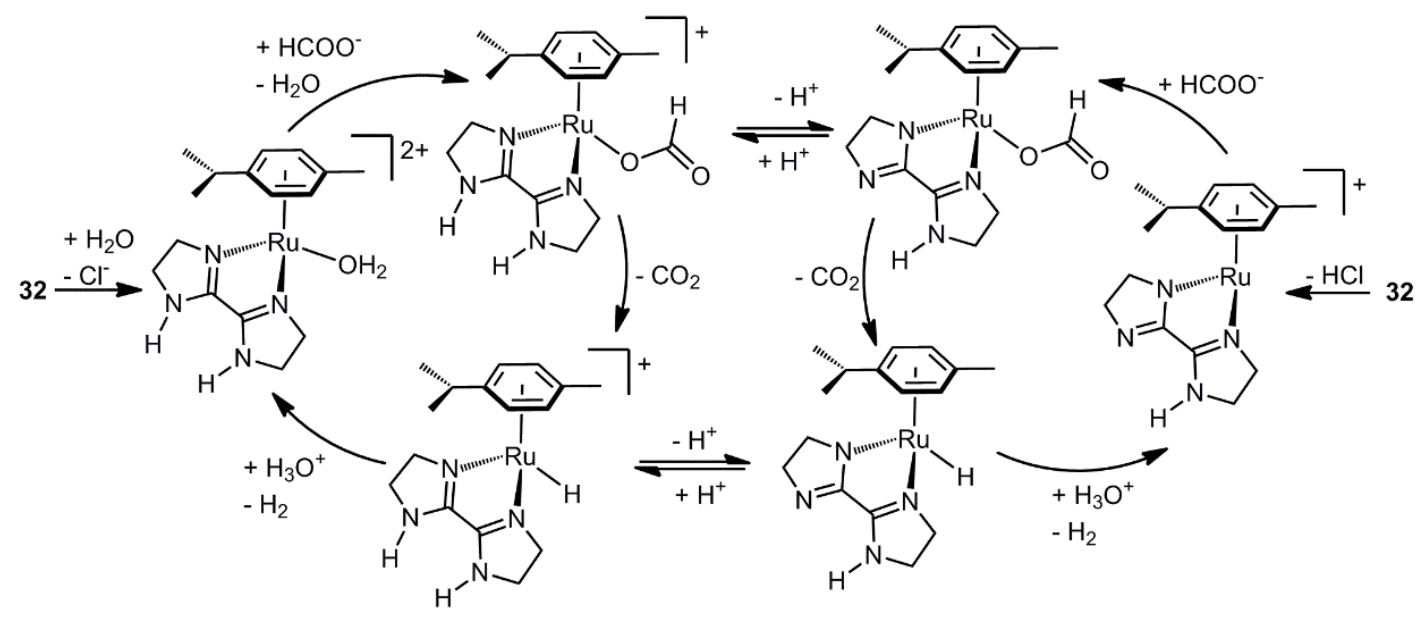

Scheme 18. Proposed catalytic cycles with pre-catalysts $32 .{ }^{[39]}$

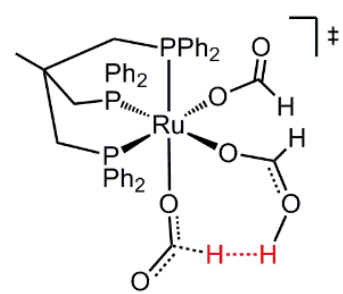

Figure 9. Depiction of the transition state that entails the cleavage of the formate's $\mathrm{C}-\mathrm{H}$ bond. ${ }^{[38]}$

Huang et al. reported two plausible pathways depending on the reaction conditions, both based on mononuclear Ru species. ${ }^{[39]}$ In aqueous FA, complex 32 (Figure 10) catalyzes the dehydrogenation of $\mathrm{HCOOH}$ or an aqueous mixture $\mathrm{HCOOH} / \mathrm{HCOO}^{-}$at $90{ }^{\circ} \mathrm{C}$.

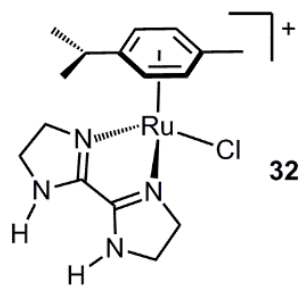

Figure 10. Depiction of pre-catalysts 32

The mechanism described in Scheme 18 (left-hand side cycle) was proposed to occur in the absence of formate, while that on the right would take place in a more basic media (mixtures $\left.\mathrm{HCOOH} / \mathrm{HCOO}^{-}\right)$. The pre-activation of 32 requires the substitution of the chloride ligand by a water molecule (left-hand side cycle) or the elimination of $\mathrm{HCl}$ (righ-hand side cycle). The latter would take place via ligand deprotonation by a formate ion. Subsequently, formation of a formate complex occurs followed by $\mathrm{CO}_{2}$ elimination via hydride abstraction (Figure 11). Finally, $\mathrm{H}_{2}$ elimination takes place by means of hydride protonation with $\mathrm{H}_{3} \mathrm{O}^{+}$ (by means of an outer-sphere step), which concomitantly regenerates the active species.

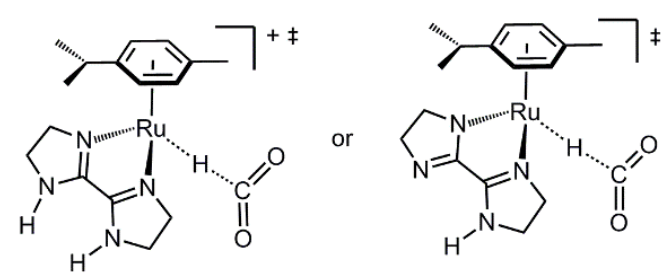

Figure 11. Depiction of the transition states proposed for the hydride abstraction step. ${ }^{[39]}$

Huang et al. also reported a metal-ligand cooperative mechanism using complex 33, which features a pincer ligand containing noninnocent side arms. ${ }^{[40]}$ The proposed mechanism entails the aromatization-dearomatization of the pincer ligand during the course of the catalytic cycle (Scheme 19).
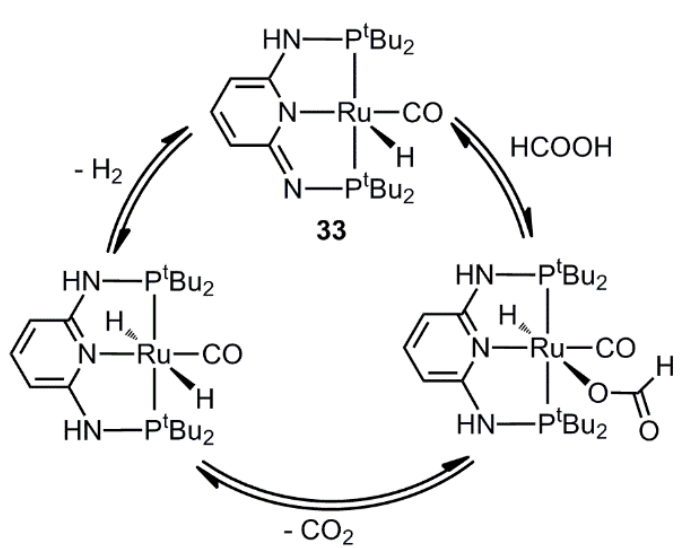

Scheme 19. Proposed catalytic cycles with pre-catalysts $33{ }^{[40]}$

The first step requires the protonation of the imine nitrogen at the side arm (aromatization), followed by coordination of the thus formed formate ion. Subsequently, the decarboxylation of the formate ligand takes place, this being the rate limiting step 
according to KIE studies. The trans-dihydrido complex eliminates $\mathrm{H}_{2}$ via ligand dearomatization.

It is worth mentioning that the oxidation of the Ru center remains +2 throughout the catalytic cycle, which has been proposed to account for the absence of decarbonylation reaction. Moreover, the presence of the side arms was invoked in order to explain the stability of this catalyst. According to the authors, the steric bulk of the $t$-Bu groups and the presence of the $\mathrm{NH}$ moieties would decrease the possibility of an $\mathrm{H}^{+}$attack at the metal center.

\section{Rhodium Catalysts}

Rhodium complexes have shown worse performances than their iridium and ruthenium counterparts in the catalytic dehydrogenation of FA, plausibly due to their low stability. ${ }^{[97]}$ However, some interesting mechanistic studies on Rh-complexes have been published.

The water soluble complexes 34a-f proved active for the selective dehydrogenation of $\mathrm{FA}$ at room temperature in aqueous solution (Figure 12). ${ }^{[41]}$

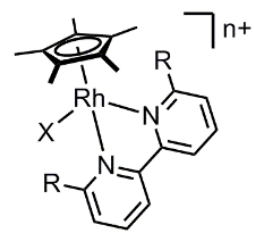

$$
\begin{aligned}
& \text { 34a }\left(X=\mathrm{H}_{2} \mathrm{O} ; \mathrm{R}=\mathrm{H} ; \mathrm{n}=2\right) \\
& \text { 34b }\left(X=\mathrm{HCOO}^{-} ; \mathrm{R}=\mathrm{H} ; \mathrm{n}=1\right) \\
& \text { 34c }\left(X=\mathrm{H}^{-} ; \mathrm{R}=\mathrm{H} ; \mathrm{n}=1\right) \\
& \text { 34d }\left(X=\mathrm{H}_{2} \mathrm{O} ; \mathrm{R}=\mathrm{Me} ; \mathrm{n}=2\right) \\
& \text { 34e }\left(X=\mathrm{HCOO}^{-} ; \mathrm{R}=\mathrm{Me} ; \mathrm{n}=1\right) \\
& \text { 34f }\left(X=\mathrm{H}^{-} ; \mathrm{R}=\mathrm{Me} ; \mathrm{n}=1\right)
\end{aligned}
$$

Figure 12. Depiction of complexes 34a-f.

The activity of these catalysts depends to a great extent on the $\mathrm{pH}$ of the reaction mixture, the highest TOF being obtained at $\mathrm{pH}$ 3.8. Moreover, above the $\mathrm{pK}_{\mathrm{a}}$ value of $\mathbf{3 4}$ the catalytic activity drops drastically due to the formation of the hydroxide complex $\left[\mathrm{Rh}(\mathrm{bpy})\left(\mathrm{Cp}^{*}\right)(\mathrm{OH})\right]^{+} \quad\left(\right.$ bpy $=2,2^{\prime}$-bipyridine, $\mathrm{Cp}^{*}=$ pentamethylcyclopentadienyl). This suggests that the formation of $\mathrm{H}_{2}$ requires the participation of an acid. The catalytic cycle, based on the identification of intermediates and deuteration experiments (including KIE studies), is based on the less acidic nature of the metal hydride compared to Ir analogues, which enables its protonation under the reaction conditions. ${ }^{[42]}$ The first step of the mechanism entails the formation of a formato complex, followed by elimination of $\mathrm{CO}_{2}$ (the rate limiting step). Finally, protonation of the hydrido complex thus generated leads to $\mathrm{H}_{2}$ formation. The cycle is closed upon coordination of the water molecule at the vacant coordination site left by the release of $\mathrm{H}_{2}$ (Scheme 20).

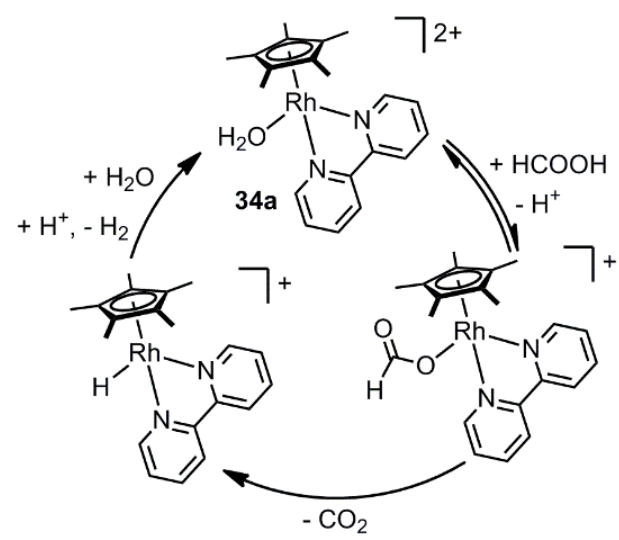

Scheme 20. Proposed catalytic cycles with pre-catalysts $34 a^{[42]}$

A cooperative mechanism that entails the reversible cyclometallation of a phenyl moiety was proposed for pincer complex 35 (Scheme 21; pathway A). ${ }^{[33]}$ However, a classical mechanism should not be discarded (Scheme 21; pathway B); in fact, the theoretical calculations performed by the authors suggest that both mechanisms co-exist under the reaction conditions.

Both pathways involve initially the reaction of 35 with $\mathrm{HCOOH}$ to afford the corresponding formato intermediate (resting state) via protonation of the cyclometallated phenyl ring. Subsequently, the authors propose a $\beta$-hydride elimination step to afford the hydrido $\mathrm{Rh}(\mathrm{I})$ intermediate and a molecule of $\mathrm{CO}_{2}$, this being the rate limiting step for both pathways. Oxidative addition of $\mathrm{HCOOH}$ followed by reductive elimination of $\mathrm{H}_{2}$ from the $\mathrm{Rh}(\mathrm{III})$ intermediate close the classical cycle. The cooperative mechanism, on the other hand, generates a Rh(III) dihydride that leads to the formation of $\mathrm{H}_{2}$ via cyclometallation of the $\mathrm{Ph}$ group. Remarkably, complex $\mathbf{3 5}$ operates under base-free conditions in dioxane at $75^{\circ} \mathrm{C}$. However, the use of a catalyst that features a methyl group instead of a phenyl group as side-arm leads to low conversions in the absence of base. Further proof for the importance of reversible coordination in these systems is the fact that the use of NNP and PCP ligands results in inhibition of the catalytic activity.

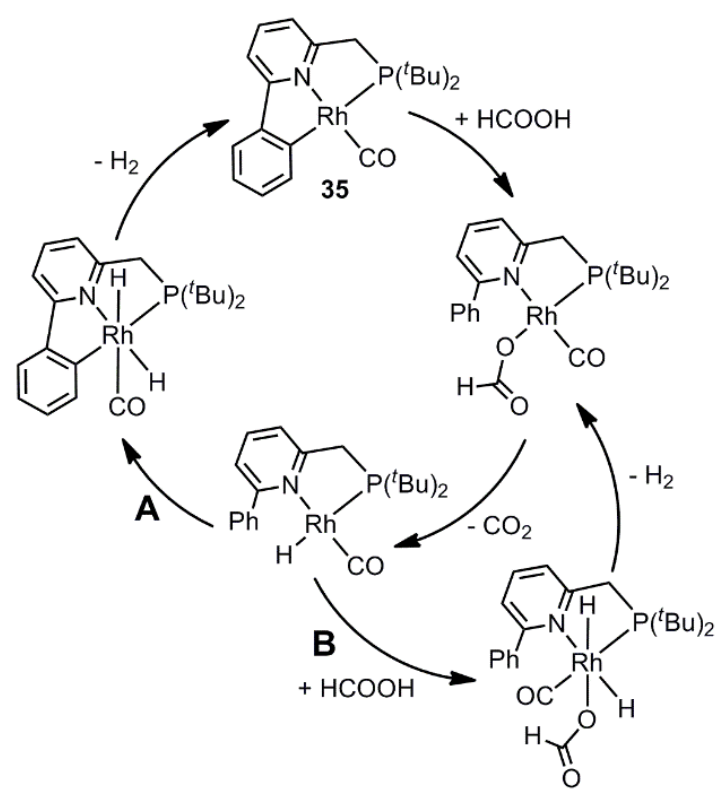


Scheme 21. Catalytic cycles proposed for pre-catalysts $35^{[43]}$

The influence of the halide and, more specifically, the promoting effect of the iodide anion was described by Xiao et al. for a rhodium(III) pre-catalyst, namely $\left[\mathrm{RhCp}^{*} \mathrm{Cl}_{2}\right]_{2}$, and also for $[\mathrm{Ru}(p$ cymene) $\left.\mathrm{Cl}_{2}\right]_{2}{ }^{[44]}$ The addition of iodide salts proved to enhance the reaction rate in $\mathrm{FA} / \mathrm{Et}_{3} \mathrm{~N}$ azeotrope; for example, the addition of $\mathrm{KI}$ to $\left[\mathrm{RhCp}^{*} \mathrm{Cl}_{2}\right]_{2}$ results in an increase of the initial TOF from $625 \mathrm{~h}^{-1}$ to $4375 \mathrm{~h}^{-1}$. This effect was attributed to fact that iodide is a better ligand than chloride and, consequently, stabilizes more efficiently the transition state of the decarboxylation step-likely an ion pair formed by dissociation of the formato ligand.

\section{Iron Catalysts}

Most of the homogeneous catalysts so far developed for FA dehydrogenation are based on noble metals; however, the catalytic activity of the more abundant and affordable non-noble metal complexes has been less explored.

A remarkable example of non-precious-metal catalyst for FA dehydrogenation is the highly active iron complex 36 , which operates in propylene carbonate, a biodegradable and non-toxic solvent, with a catalyst loading of $0.01 \mathrm{~mol} \%$ at $40{ }^{\circ} \mathrm{C}$. ${ }^{[45]}$

The authors proposed two alternative mechanisms that co-exist under catalytic conditions (Scheme 22, cycles A and B). Cycle A in Scheme 21 requires the protonation of 36 by $\mathrm{HCOOH}$ to give a formato complex and $\mathrm{a}_{2}$ molecule. Subsequently, $\beta$-hydride elimination affords a hydride complex with a $\mathrm{CO}_{2}$ ligand. Finally, release of the $\mathrm{CO}_{2}$ ligand regenerates 36 . In the case of cycle $\mathbf{B}$, coordination of formate to $\mathbf{3 6}$ occurs, followed by $\beta$-hydride elimination to render a hydride-dihydrogen complex and a molecule of $\mathrm{CO}_{2}$. Elimination of $\mathrm{H}_{2}$ regenerates 36 , closing the catalytic cycle.

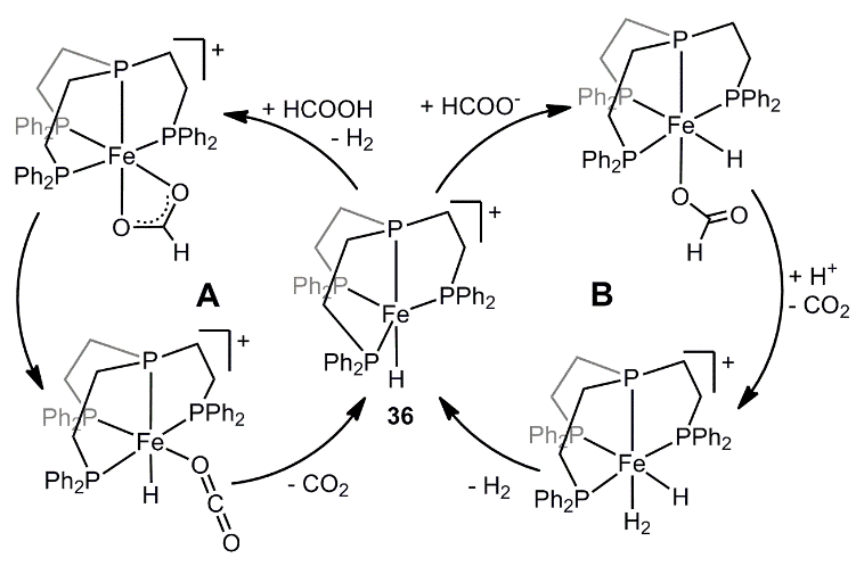

Scheme 22. Competitive catalytic cycles proposed for catalyst $36 .{ }^{[45]}$

According to the studies performed by the authors, the $\beta$-hydride elimination is the rate limiting step in both cycles.

Detailed theoretical calculations on this system were published by Ahlquist et al. ${ }^{[6]}$ and Yang. ${ }^{[47]}$ For cycle A (Scheme 22), both authors propose the coordination of FA followed by an $\mathrm{Fe}-\mathrm{H}^{-}$ $\delta \ldots \mathrm{H}^{+} \bar{\delta}_{-} \mathrm{O}$ interaction that results in the formation of an intermediate featuring a $\mathrm{H}_{2}$ and a formate ligand (Figure 13). The formation of $\mathrm{CO}_{2}$ occurs, according to both authors, via a $\beta$ hydride elimination step, which is the rate determining step.

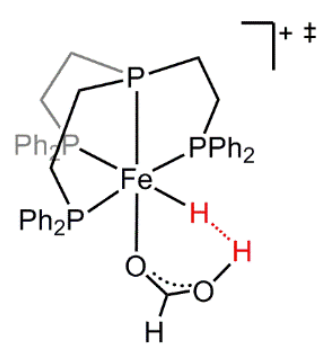

Figure 13. Transition state proposed for the formation of $\mathrm{H}_{2}$ in cycle $\mathbf{A}{ }^{[46,47]}$

In the case of cycle B (Scheme 21), the results of the theoretical calculations performed by Ahlquist et al. and Yang diverge noticeably. The former postulates a $\beta$-hydride elimination reaction after formate coordination, while the latter proposes a hydride abstraction, owing to the fact that the author was unable to locate a transition state for $\beta$-hydride elimination step. This results in two different rate limiting steps, the hydride abstraction for the mechanism proposed by $\mathrm{Yang}$ and the $\mathrm{H}_{2}$ release for that postulated by Ahlquist et al.. Remarkably, Ahlquist and coworkers performed KIE studies that support $\mathrm{H}_{2}$ release as the rate limiting step. The overall free-energy barrier for cycle $\mathbf{B}$ is higher than that of $\mathbf{A}$ according to Yang's work, although both mechanisms were proposed to co-exist. The opposite was proposed by Ahlquist and co-workers, suggesting that cycle $\mathbf{B}$ should be preferred over $\mathbf{A}$ due to the significant energy barrier calculated for both processes $\left(30.6 \mathrm{Kcal} \mathrm{mol}^{-1}\right.$ for $\mathbf{A}$ and $20.6 \mathrm{Kcal}$ $\mathrm{mol}^{-1}$ for $\left.\mathbf{B}\right)$.

Fe-complexes supported by pincer ligands have shown good performances in FA dehydrogenation. Pincer complex 37 operates at $40{ }^{\circ} \mathrm{C}$ in the presence of $50 \mathrm{~mol}^{\circ} \mathrm{Et}_{3} \mathrm{~N}$ in various organic solvents, namely, tetrahydrofurane, dimethyl sulfoxide and 1,4-dioxane. ${ }^{[48]}$ The authors proposed a mechanism based on stoichiometric and catalytic experiments, in addition to theoretical calculations. The catalytic cycle entails as first step the protonation of the dihydride complex 37 to give a dihydrogen complex. Subsequently, $\mathrm{H}_{2}$ dissociation leaves a vacant coordination site that is occupied by a formate ion to give formato complex 38, which was also used a competent catalyst for this transformation. The $\mathrm{CO}_{2}$ elimination step that regenerates $\mathbf{3 7}$ was proposed to take place via hydride abstraction, since $\beta$-hydride elimination would require the dissociation of one of the phosphine side arms (Scheme 23). 


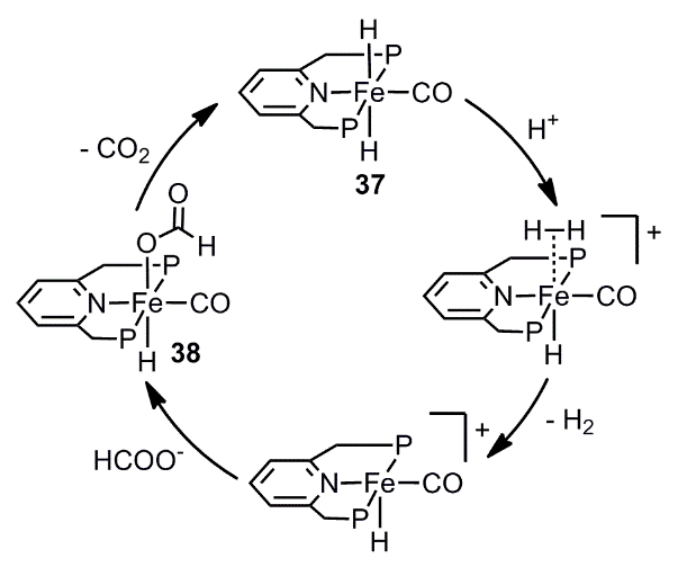

Scheme 23. Proposed catalytic cycle for the dehydrogenation of FA by complex $36\left(\mathrm{P}=\mathrm{P}^{\mathrm{t}} \mathrm{Bu} \mathrm{u}_{2}\right){ }^{[48]}$

Complexes $\mathbf{3 9}$ and $\mathbf{4 0}$ (Scheme 24) were tested under analogous conditions, showing similar activities that were significantly increased by adding catalytic amounts of a Lewis acid (10 mol\%). ${ }^{[49]}$ In the presence of a Lewis acid as co-catalyst $\left(\mathrm{Li}^{+}, \mathrm{Na}^{+}\right.$ and $\mathrm{Cs}^{+}$showed the best performances), the reaction takes place at $80{ }^{\circ} \mathrm{C}$ in 1,4-dioxane under base-free conditions, allowing TONs ca. 1000000 and TOFs ca. 200000.

The catalytic cycle proposed by the authors is analogous to that depicted in Scheme 22, with the difference that the decarboxylation, which takes place via a hydride abstraction step, is aided by a Lewis acid (LA) and the activation of FA happens by means of a ligand-metal cooperative mechanism (Scheme 23).

The related Fe-pincer pre-catalyst $\mathbf{4 1}$ also showed good activities in various organic solvents in the presence of $\mathrm{Et}_{3} \mathrm{~N}$. The best results were obtained using $100 \% \mathrm{Et}_{3} \mathrm{~N}$ at $80 \stackrel{\circ}{\circ} \mathrm{C}$ in propylene carbonate $(T O N=10000) .{ }^{[50]}$ The catalytic cycle was proposed based on the identification of the intermediate species 42-44, theoretical calculations and previous results by the same authors in the reverse reaction, $\mathrm{CO}_{2}$ hydrogenation ${ }^{[51]}$ (Scheme 25).

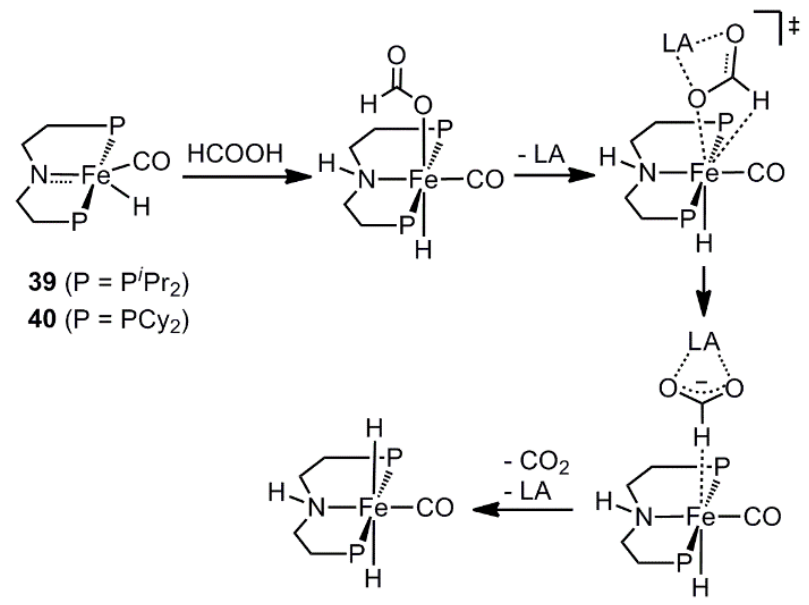

Scheme 24. Proposed Lewis-acid-assisted reaction mechanism for catalysts 39 and $40 .[49]$

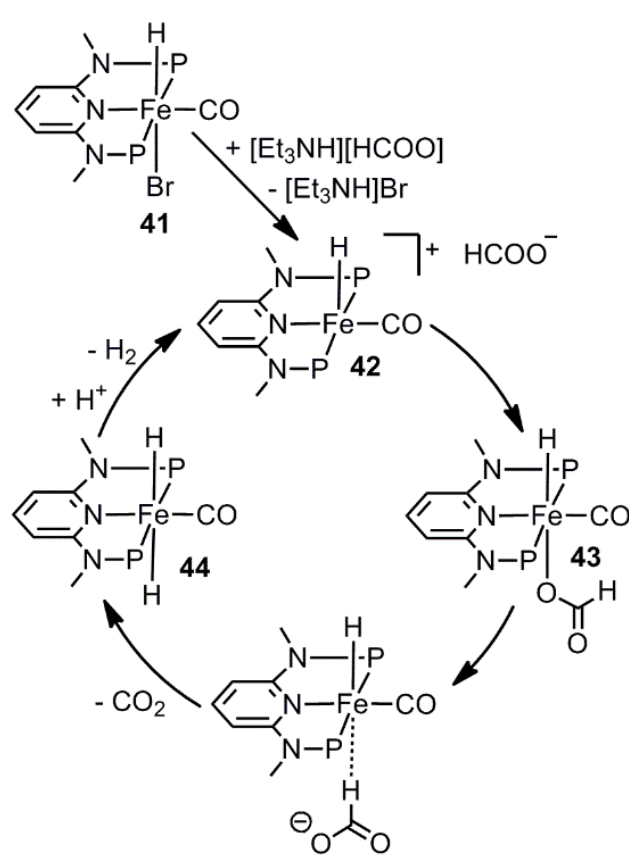

Scheme 25. Proposed catalytic cycle for the dehydrogenation of FA by complex $41\left(\mathrm{P}=\mathrm{P}^{\mathrm{i}} \mathrm{Pr} 2\right) \cdot{ }^{[50]}$

The first step entails the formation of the active species (42) from the pre-catalyst (41) via bromide abstraction. The resulting unsaturated species undergoes the coordination of the formate counterion (43). Subsequently, $\mathrm{CO}_{2}$ elimination takes place by means of a hydride abstraction step to afford 44 . The elimination of a $\mathrm{H}_{2}$ molecule occurs upon protonation of $\mathbf{4 4}$, with concomitant regeneration of the active species.

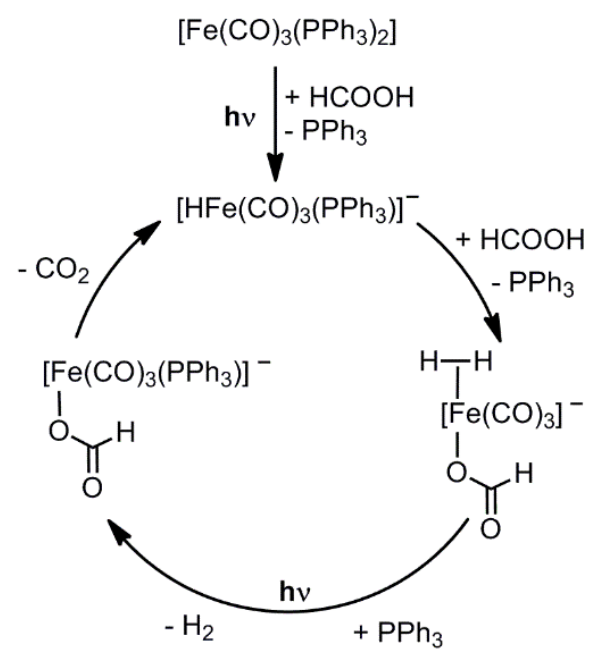

Scheme 26. Proposed catalytic cycle for the dehydrogenation of FA by complex 45 under visible-light irradiation. ${ }^{[52 a]}$

Catalysts for FA dehydrogenation under photolytic conditions have also been reported, although their potential for industrial application is limited. ${ }^{[52]}$ Detailed mechanistic studies on precatalyst $\left[\mathrm{Fe}(\mathrm{CO})_{3}\left(\mathrm{PPh}_{3}\right)_{2}\right](45)^{[52 a]}$ suggest that irradiation with visible light affords the active species $\left[\mathrm{HFe}(\mathrm{CO})_{3}\left(\mathrm{PPh}_{3}\right)\right]^{-}$, which readily dissociates a $\mathrm{PPh}_{3}$ ligand to permit formate coordination 
(Scheme 26). Subsequent protonation of the hydride leads to the formation of a dihydrogen ligand that is released by visible light irradiation and followed by $\mathrm{PPh}_{3}$ coordination. ${ }^{[53]}$ Finally, $\mathrm{CO}_{2}$ elimination to afford the active species was proposed to occur via $\beta$-hydride elimination.

\section{Conclusions}

In this review we have revisited the most relevant mechanisms so far postulated for homogeneously catalyzed FA dehydrogenation processes. The most prolific metal centers are Ir, Ru, Rh and Fe. However, other metal complexes not mentioned here, such as $\mathrm{Al},{ }^{[54]}$ show great potential for the synthesis of inexpensive and sustainable catalysts for this process. It is noteworthy that many of the catalysts presented in this work operate in aqueous solutions, which is relevant to fuel-cell applications and also because the presence of water may be crucial from a mechanistic viewpoint.

A great variety of mechanisms seem to operate in FA dehydrogenation processes. Even though the nature of the catalytic cycles is often very different and, consequently, direct comparison between them is problematic, we consider that the main divergences that, to some degree, determine the type of mechanism are: (i) The nuclearity of the active species, which may trigger mononuclear or dinuclear mechanisms; (ii) The formation of $\mathrm{CO}_{2}$, which may happen by $\beta$-hydride elimination, hydride abstraction or outer-sphere mechanisms; (iii) The rate limiting step, which is usually related to the processes of $\mathrm{CO}_{2}$ or $\mathrm{H}_{2}$ formation.

What appears to be common ground is that outer-sphere interactions are often key for the success of the reaction. Some remarkable cases are:

1) The hydride abstraction step may be assisted by Lewis acids that interact with the oxygen atoms of the formate, thus facilitating the heterolytic splitting of the $\mathrm{C}-\mathrm{H}$ bond.

2) The formation of $\mathrm{H}_{2}$, which has been frequently proposed to occur by protonation of a hydrido ligand with $\mathrm{H}_{2} \mathrm{O}, \mathrm{HCOOH}$ or $\mathrm{H}_{3} \mathrm{O}^{+}$.

3) Ligand assisted deprotonation of FA's $\mathrm{OH}$ moiety by protonresponsive ligands.

4) Dimeric $\mathrm{HCOOH} \cdots \mathrm{HCOOH}$ interactions that allow remote metal-ligand cooperation.

5) Outer-sphere cleavage of FA's C-H bond instead of $\beta$-hydride elimination or hydride abstraction.

With this knowledge in hand, we believe that the design of tailored metal-ligand systems that harness the potential of outer-sphere interactions are crucial to enhance the activity of current catalysts. Moreover, the use of these interactions may boost the performance of non-noble-metal-catalysts, thus promoting more sustainable processes.

\section{Acknowledgements}

This work was supported by the Spanish Ministry of Economy and Competitiveness ("Ramón y Cajal" programme (M.I.)) and the DGA/FSE-E07. The support from the KFUPM-University of Zaragoza research agreement and the Centre of Research Excellence in Petroleum Refining \& KFUPM is gratefully acknowledged.
Keywords: Hydrogen • FA • Carbon dioxide• Mechanism • dehydrogenation

[1] G. W. Huber, S. Iborra, A. Corma, Chem. Rev. 2006, 106, 4044-4098.

[2] a) P. Grant, Nature 2003, 424, 129-130; b) M. S. Dresselhaus, I. L. Thomas, Nature 2001, 414, 332-337.

[3] N. Chouhan, R.-S. Liu, J. Zhang, Photochemical Water Splitting Materials and Applications, Taylor \& Francis Group, Boca Ratón, 2017.

[4] M. M. Mench, Fuel Cell Engines, Wiley-VCH, Weinheim, Germany, 2008.

[5] a) B. Loges, A. Boddien, F. Gärtner, H. Junge, M. Beller, Top. Catal. 2010, 53, 902-914; b) T. He, P. Pachfule, H. Wu, Q. Xu, P. Chen, Nat. Rev. Mater. 2016, 1, 16059.

[6] F. Joó, ChemSusChem 2008, 1, 805-808

[7] a) B. Loges, A. Boddien, H. Junge, M. Beller, Angew. Chem. Int. Ed. 2008, 47, 3962-3965; b) C. Fellay, P. J. Dyson, G. Laurenczy, Angew. Chem. Int. Ed. 2008, 47, 3966-3968; c) T. C. Johnson, D. J. Morris, M. Wills, Chem. Soc. Rev. 2010, 39, 81-88.

[8] G. Laurenczy, P.J. Dyson, J. Braz. Chem. Soc. 2014, 25, 2157-2163.

[9] a) P. G. Jessop, T. Ikariya, R. Noyori, Chem. Rev. 1995, 95, 259-272; b) W. Leitner, Angew. Chem. Int. Ed. Engl. 1995, 34, 2207-2221; c) B. Loges, A. Boddien, F. Gärtner, H. Junge, M. Beller, Top. Catal. 2010, 53, 902-914; d) P. G. Jessop, F. Joó, C.-C. Tai, Coord. Chem. Rev. 2004, 248, 2425-2442; e) M. Cokoja, C. Bruckmeier, B. Rieger, W. A Herrmann, F. E. Kühn, Angew. Chem. Int. Ed. 2011, 50, 8510-8537; f) K. Sordakis, C. Tang, L. K. Vogt, H. Junge, P. J. Dyson, M. Beller, G. Laurenczy, Chem. Rev. 2018, 118, 372-433.

[10] D. J. Drury in FA and Derivatives. Kirk-Othmer Encyclopedia of Chemical Technology, Vol. 27 (Eds.: J. I. Kroschwitz and M. Howe-Grant), John Wiley \& Sons, Inc.: New York, 2013.

[11] a) W.-H. Wang, Y. Himeda, J. T. Muckerman, G. F. Manbeck, E. Fujita, Chem. Rev. 2015, 115, 12936-12973; b) G. Laurenczy, P. J. Dyson, J. Braz. Chem. Soc., 2014, 25, 2157-2163.

[12] R. S. Coffey, Chem. Commun. 1967, 923-924.

[13] R. S. Paonessa, W. C. Trogler, J. Am. Chem. Soc. 1982, 104, 35293530 .

[14] a) Y. Gao, J. Kuncheria, G. P. A. Yap, R. J. Puddephatt, Chem. Commun., 1998, 2365-2366; b) Y. Gao, J. K. Kuncheria, H. A. Jenkins, R. J. Puddephatt, G. P. A. Yap, J. Chem. Soc., Dalton Trans., 2000, 3212 3217; c) K. Almeida Leñero, M. Kranenburg, Y. Guari, P. C. J. Kamer, P. W. N. M. van Leeuwen, S. Sabo-Etienne, B. Chaudret, Inorg. Chem. 2003, 42, 2859-2866; d) Y. Gao, M. C. Jennings, R. J. Puddephatt, Organometallics 2001, 20, 1882-1888.

[15] a) F. J. Fernández-Alvarez, M. Iglesias, L. A. Oro, V. Polo; ChemCatChem 2013, 5, 3481-3494; b) R. M. Bullock, M. H. Voges, J. Am. Chem. Soc. 2000, 122, 12594-12595.

[16] M. Iglesias, E. Sola, L. A. Oro, Top. Organomet. Chem. 2015, 59, 31-58.

[17] S. Komiya, T. Yasuda, A. Fukuoka, M. Hirano, J. Mol. Catal. A 2000, 159, 63-70.

[18] M. L. Man, Z. Zhou, S. M. Ng, C. P. Lau, Dalton Trans., 2003, 37273735 .

[19] a) S. Oldenhof, J. I. van der Vlugt, J. N. H. Reek, Catal. Sci. Technol., 2016, 6, 404-408; b) S. Oldenhof, M. Lutz, B. de Bruin, J. I. van de Vlugta, J. N. H. Reek, Chem. Sci., 2015, 6, 1027-1034; c) S. Oldenhof, B. de Bruin, M. Lutz, M. A. Siegler, F. W. Patureau, J. I. van der Vlugt, J. N. H. Reek, Chem. Eur. J. 2013, 19, 11507-11511.

[20] a) W.-H. Wang, S. Xu, Y. Manaka, Y. Suna, H. Kambayashi, J. T. Muckerman, E. Fujita, Y. Himeda, ChemSusChem 2014, 7, 1976-1983; b) Y. Suna, M. Z. Ertem, W.-H. Wang, H. Kambayashi, Y. Manaka, J. T. Muckerman, E. Fujita, Y. Himeda, Organometallics 2014, 33, 65196530 .

[21] S. Siek, D. B. Burks, D. L. Gerlach, G. Liang, J. M. Tesh, C. R. Thompson, F. Qu, J. E. Shankwitz, R. M. Vasquez, N. Chambers, G. J. Szulczewski, D. B. Grotjahn, C. E. Webster, E. T. Papish, Organometallics 2017, 36, 1091-1106.

[22] M. Iguchi, H. Zhong, Y. Himeda, H. Kawanami, Chem. Eur. J. 2017, 23, 17017-17021.

[23] J. F. Hull, Y. Himeda, W.-H. Wang, B. Hashiguchi, R. Periana, D. J. Szalda, J. T. Muckerman, E. Fujita, Nat. Chem. 2012, 4, 383-388.

[24] Y. Himeda, Green Chem. 2009, 11, 2018-2022. 
[25] J. H. Barnard, C. Wang, N. G. Berry, J. Xiao, Chem. Sci. 2013, 4, 12341244.

[26] a) T. Ikariya, K. Murata, R. Noyori, Org. Biomol. Chem. 2006, 4, 393406; b) R. Noyori, M. Yamakawa S. Hashiguchi, J. Org. Chem. 2001, 66, 7931-7944.

[27] J. Li, J. Li, D. Zhang, C. Liu, ACS Catal. 2016, 6, 4746-4754.

[28] S. Scheiner, Hydrogen Bonding; Oxford University Press: New York, 1997.

[29] A. Matsunami, Y. Kayaki, T. Ikariya Chem. Eur. J. 2015, 21, 1351313517.

[30] A. Matsunami, S. Kuwata, Y. Kayaki, ACS Catal. 2017, 7, 4479-4484.

[31] J. J. A. Celaje, Z. Lu, E. A. Kedzie, N. J. Terrile, J. N. Lo, T. J. Williams, Nat. Commun. 2016, 7, 11308.

[32] S. Fukuzumi, T. Kobayashi, T. Suenobu, J. Am. Chem. Soc. 2010, 132 , 1496-1497.

[33] S. Cohen, V. Borin, I. Schapiro, S. Musa, S. De-Botton, N. V. Belkova, D. Gelman, ACS Catal. 2017, 7, 8139-8146.

[34] a) Y. Maenaka, T. Suenobu, S. Fukuzumi, Energy Environ. Sci., 2012, 5 , 7360-7367; b) R.Tanaka, M. Yamashita, L. W. Chung, K. Morokuma, K. Nozaki, Organometallics 2011, 30, 6742-6750.

[35] a) S.-F. Hsu, S. Rommel, P. Eversfield, K. Muller, E. Klemm, W. R. Thiel, B. Plietker, Angew. Chem. Int. Ed. 2014, 53, 7074-7078; b) K. Sordakis, A. F. Dalebrook, G. Laurenczy, ChemCatChem 2015, 7, 2332-2339; c) A. Boddien, B. Loges, H. Junge, M. Beller, ChemSusChem 2008, 1, 751758; d) N. H. Anderson, J. M. Boncella, A. M. Tondreau, Chem. Eur. J. 2017, 23, 13617-13622.

[36] D. J. Morris, G. J. Clarkson, M. Wills, Organometallics 2009, 28, 41334140.

[37] C. Fellay, N. Yan, P. J. Dyson, G. Laurenczy, Chem. Eur. J. 2009, 15, 3752-3760.

[38] a) I. Mellone, M. Peruzzini, L. Rosi, D. Mellmann, H. Junge, M. Beller, L. Gonsalvi, Dalton Trans. 2013, 42, 2495-2501; b) G. Manca, I. Mellone, F. Bertini, M. Peruzzini, L. Rosi, D. Mellmann, H. Junge, M. Beller, A lenco, L. Gonsalvi, Organometallics 2013, 32, 7053-7064.

[39] C. Guan, D.-D. Zhang, Y. Pan, M. Iguchi, M. J. Ajitha, J. Hu, H. Li, C. Yao, M.-H. Huang, S. Min, J. Zheng, Y. Himeda, H. Kawanami, K.-W Huang, Inorg. Chem. 2017, 56, 438-445.
[40] Y. Pan, C.-L. Pan, Y. Zhang, H. Li, S. Min, X. Guo, B. Zheng, H. Chen, A. Anders, Z. Lai, J. Zheng, K.-W. Huang, Chem. Asian J. 2016, 11 1357-1360.

[41] S. Fukuzumi, T. Kobayashi, T. Suenobu, ChemSusChem 2008, 1, 827834.

[42] a) S. Ogo, N. Makihara, Y. Kaneko, Y. Watanabe, Organometallics 2001 20, 4903; b) T. Abura, S. Ogo, Y. Watanabe, S. Fukuzumi, J. Am. Chem. Soc. 2003, 125, 4149-4154; c) T. Suenobu, D. M. Guldi, S. Ogo, S Fukuzumi, Angew. Chem. 2003, 115, 5650; Angew. Chem. Int. Ed. 2003 42, 5492; d) S Ogo, K. Uehara, T .Abura, S. Fukuzumi, J. Am. Chem. Soc. 2004, 126, 3020-3021.

[43] L. S. Jongbloed, B. de Bruin, J. N. H. Reek, M. Lutz, J. I. van der Vlugt, Catal. Sci. Technol. 2016, 6, 1320-1327.

[44] Z. Wang, S.-M. Lu, J. Wu, C. Li, J. Xiao, Eur. J. Inorg. Chem. 2016, 490 496.

[45] A. Boddien, D. Mellmann, F.Gärtner, R. Jackstell, H. Junge, P. J. Dyson, G. Laurenczy, R. Ludwig, M. Beller, Science 2011, 333, 1733-1736.

[46] R.Sánchez-de-Armas, L. Xue, M. S. G. Ahlquist, Chem. Eur. J. 2013, 19, 11869-11873.

[47] X. Yang, Dalton Trans. 2013, 42, 11987-11991.

[48] T. Zell, B. Butschke, Y. Ben-David, D. Milstein Chem. Eur. J. 2013, 19, 8068-8072.

[49] E. A. Bielinski, P. O. Lagaditis, Y. Zhang, B. Q. Mercado, C. Würtele, W. H. Bernskoetter, N. Hazari, S. Schneider, J. Am. Chem. Soc. 2014, 136 10234-10237.

[450] I. Mellone, N. Gorgas, F. Bertini, M. Peruzzini, K. Kirchner, L. Gonsalvi, Organometallics 2016, 35, 3344-3349.

[51] F. Bertini, N. Gorgas, B. Stöger, M. Peruzzini, L. F Veiros, K. Kirchner, L. Gonsalvi, ACS Catal. 2016, 6, 2889-2893.

[52] a) A. Boddien, B. Loges, F. Gärtner, C. Torborg, K. Fumino, H. Junge, R Ludwig, M. Beller, J. Am. Chem. Soc. 2010, 132, 8924-8934; b) A Boddien, F. Gärtner, R. Jackstell, H. Junge, A. Spannenberg, W. Baumann, R. Ludwig, M. Beller, Angew. Chem. Int. Ed. 2010, 49, 89938996.

[53] R. L. Sweany, J. Am. Chem. Soc. 1981, 103, 2410-2412.

[54] T. W. Myers, L. A. Berben, Chem. Sci. 2014, 5, 2771-2777 
